INEEL/EXT-99-01023

December 1999

\title{
OPTIONS FOR GAS-TO-LIQUIDS TECHNOLOGY IN ALASKA
}

\author{
E. P. Robertson
}




\title{
Options for Gas-to-Liquids Technology in Alaska
}

\author{
E. P. Robertson
}

Published December 1999

Idaho National Engineering and Environmental Laboratory Bechtel BWXT Idaho, LLC Idaho Falls, Idaho 83415

Prepared for the

U.S. Department of Energy Office of Fossil Energy Under DOE Idaho Operations Office

Contract DE-AC07-99ID13727 


\section{ABSTRACT}

The Alaska North Slope (ANS) holds a vast resource of natural gas but has no current method of transportation from the North Slope to world markets. The Prudhoe Bay field contains the largest portion of the discovered natural gas on the North Slope or about $21.8 \mathrm{Tcf}$ of natural gas available for sale after $\mathrm{CO}_{2}$ removal and satisfying power requirements and other North Slope use. The natural gas at Prudhoe Bay that is produced during oil production operations is reinjected and used to increase oil recovery. Currently, there are two broad gas-marketing schemes proposed for commercializing the natural gas on the North Slope. One is a gas-pipeline/liquefied natural gas (LNG) plant scenario; the other is a gas-toliquids (GTL) option that chemically converts the natural gas to a stable, liquid syn-crude in a North Slope plant, eliminating the need for an additional pipeline from the North Slope to a southern Alaska port.

The purposes of this report were to assess the effect of applying new technology to the economics of a proposed GTL plant, to evaluate the potential of a slower-paced, staged deployment of GTL technology, and to evaluate the effect of GTL plant placement on economics.

Five scenarios were economically evaluated and compared: a no-major-gas-sales scenario, a gaspipeline/LNG scenario, a fast-paced GTL development scenario, a slow-paced GTL development scenario, and a scenario which places the GTL plant in lower Alaska, instead of on the North Slope. Evaluations were completed using an after-tax discounted cash flow analysis. Results indicate that the slowpaced GTL scenario is the only one with a rate of return greater than 10 percent. The other scenarios did not show positive net present values under the economic conditions selected for the simulations. Their rank, in order of net present value, is as follows: slow-paced GTL development, no-major-gas-sales, fastpaced GTL development, a fast-paced GTL development in southern Alaska, and finally a gaspipeline/LNG project.

The slow-paced GTL development would allow cost saving on subsequent expansions. These assumed savings along with the lowering of the transportation tariff combine to distinguish this option for marketing the North Slope gas from the other scenarios. Critical variables that need further consideration include the GTL plant cost, the GTL product premium, and operating and maintenance costs. Reducing these costs, or increasing the premium, would increase the profitability of the GTL process. In addition, understanding these variables better and reducing their uncertainty would allow a more accurate prediction of economic profitability. 


\section{EXECUTIVE SUMMARY}

The Alaska North Slope (ANS) holds a vast resource of natural gas but has no current method of transportation from the North Slope to world markets. The Prudhoe Bay field contains the largest portion of the discovered natural gas on the North Slope or about $21.8 \mathrm{Tcf}$ of natural gas available for sale after $\mathrm{CO}_{2}$ removal and satisfying power requirements and other North Slope use. The natural gas at Prudhoe Bay that is produced during oil production operations is reinjected and used to increase oil recovery. Currently, there are two broad gas-marketing schemes proposed for commercializing the natural gas on the North Slope. One is a gas-pipeline/liquefied natural gas (LNG) plant scenario; the other is a gas-toliquids (GTL) option that chemically converts the natural gas to a stable, liquid syn-crude in a North Slope plant, eliminating the need for an additional pipeline from the North Slope to a southern Alaska port.

The objective of this report is to incorporate new information regarding GTL technology into an economic evaluation of a GTL plant in Alaska, and to look at the development-pace and placement of a GTL project. In some ways, this current report follows up on an Idaho National Engineering \& Environmental Laboratory report in 1996 by Thomas et al. for the Department of Energy entitled Economics of Alaska North Slope Gas Utilization Options. That 1996 DOE report analyzed a GTL scenario for marketing the ANS gas, a gas-pipeline/LNG scenario, and a no-gas-sales scenario. Since that report was published, new information regarding GTL technology was released to the public that appears to enhance the economic viability of the GTL project option for marketing ANS gas. This current report incorporates the new GTL-technology information and looks in more detail at the impact of the timing of GTL plant construction and location on the economic viability of a GTL project in Alaska.

\section{Study Purposes}

1) To apply technical advances to the GTL scenario evaluated in the 1996 DOE report to determine the effects new technology and knowledge have on the economics of the GTL project.

2) To evaluate the potential economic impact of a slower-paced, staged deployment of GTL technology on the North Slope; thus taking advantage of experience and technological improvements in later plant expansions.

3) To evaluate the concurrent development of both the LNG and GTL projects; with the GTL plant located in southern Alaska at the gas pipeline terminus.

To accomplish this, five scenarios were economically evaluated and compared: a no-major-gassales scenario, a gas-pipeline/LNG scenario, a fast-paced GTL development scenario, a staged, slowpaced GTL development scenario, and a scenario which places the GTL plant in southern Alaska, instead of on the North Slope. 


\section{Prudhoe Bay Field}

The Prudhoe Bay field is the largest field in North America and lies on the Arctic coastline about 200 miles east of Point Barrow. There were about 23 billion barrels of oil originally in place (OOIP) and $46 \mathrm{Tcf}$ of gas originally in place (OGIP). Ultimate oil-recovery estimates have been increasing over the years as more is learned about the field and enhanced oil recovery techniques and cost reduction efforts continue to improve.

Currently, Prudhoe Bay's natural gas is used to enhance oil recovery from the field. Major gas sales would take gas away from enhanced oil recovery projects and decrease ultimate oil recovery from the field. Some of the highly effective enhanced oil recovery programs that use the recycled gas are: pressure maintenance by gas re-injection, miscible injectant flooding, and water-alternating-gas programs. If major gas sales begin in 2005, a 400 million-barrel reduction in ultimate oil recovery is assumed. Major gas sales occurring later in the life of the Prudhoe Bay field would have a less significant impact on oil recovery simply because there would be less oil available to recover. Major gas sales beginning in 2010 are assumed to reduce ultimate recovery by 100 million barrels; and gas sales beginning in 2015 would have a negligible effect on oil recovery.

Of the 46 Tcf of natural gas originally in place in the Prudhoe Bay field, 30 Tcf resides in the gas cap and $16 \mathrm{Tcf}$ lies within the oil rim. Natural gas (containing $12 \% \mathrm{CO}_{2}$ ) is currently being produced at a rate of about $8 \mathrm{Bcf} / \mathrm{D}$ from $\mathrm{PBU}$ as part of oil production operations. The heavier components of the produced gas are removed and shipped to market as natural gas liquids (NGL) or used as miscible injectant to recover crude oil. Some of the lean gas is used as fuel and the remainder (about $7 \mathrm{Bcf} / \mathrm{D}$ ) is reinjected into the gas cap. Of the original $46 \mathrm{Tcf}$ in place, over $2.8 \mathrm{Tcf}$ have been used as fuel for heating or sold as NGL to date.

\section{Current Status of Gas Commercialization Efforts}

Commercializing or marketing the natural gas residing on the North Slope has been a major goal of the field operators since the Prudhoe Bay field was first unitized. Recently, efforts to arrive at an economic marketing plan have intensified. The two schemes receiving the most consideration are an LNG option and a GTL option. The LNG scheme involves constructing an 800-mile gas pipeline, an LNG facility in Valdez, AK, and shipping LNG to Asia via LNG tankers. The GTL scheme involves constructing a GTL plant on the North Slope and transporting the GTL product through TAPS and to market via regular oil tankers. However, neither scenario has been selected exclusively as the preferred method to market the large gas resource on the North Slope.

In January 1998, the Alaska Department of Natural Resources released a report entitled Alaska North Slope Gas Commercialization Team - Report to the Governor. This report discussed ways the State of Alaska and the federal government could improve the economic feasibility and competitiveness of a North Slope gas project and focused almost exclusively on the LNG option. It addressed ways the state could lower taxes or change the tax structure to increase the economic viability of a North Slope gas project.

In letters attached to the Report to the Governor, ARCO, BP, and Exxon commented on the contents of the report and general gas-commercialization efforts. ARCO expressed concern that despite the State's efforts, an LNG project may still be undercut by higher rate-of-return projects from around the world to provide anticipated Far East markets. BP encouraged the state to address the fiscal and regulatory system with respect to the emerging GTL technology as well. Exxon urged the State to maintain adequate flexibility to address the special needs of any stranded gas project, whether it be LNG or GTL. 


\section{Review of LNG with Respect to Alaska}

In 1997, total world LNG imports were 81.759 million tons, of which, 61.728 million tons went to East Asia, or $75 \%$ of world LNG imports. Japan imported 47.106 million tons, Korea imported 11.457 million tons, and Taiwan imported 3.165 million tons in 1997. Japan imports LNG from the U.S.A. (Alaska), Brunei, Abu Dhabi, Indonesia, Malaysia, Australia, and Qatar.

LNG demand in East Asia is expected to rise to 80 million tons in 2000, 100 million tons in 2005, and 130 million tons in 2010. There are many new potential LNG supply sources competing to fill this growing market. These include Qatar, Oman, and Yemen in the Middle East; Malaysia and Indonesia in Asia; the north and northwest areas of Australia; and Sakhalin and Alaska in the north Pacific. Whether an ANS gas project can compete with these or other new sources of LNG remains to be seen.

To help the commercialize the ANS gas, the state of Alaska passed the Alaska Stranded Gas Development Act in 1998 that authorized the state to negotiate payments from sponsors of the proposed gas pipeline in lieu of taxes that otherwise would be imposed. Changes in the federal tax structure and reductions in capital costs are more important to the economics of a project than changes in state tax structure. Nevertheless, the state tax restructuring enabled by the State's Stranded Gas Act would help the economics of the project, especially if combined with federal tax changes and reductions in capital costs.

\section{Review of GTL Technologies}

The GTL process evaluated in the 1996 DOE report was taken from information regarding the Shell middle-distillate synthesis technology. Since that time, several competing technologies have been publicly discussed that could significantly improve the economics of GTL technology.

Most of the new GTL information has come from Exxon and Syntroleum, two companies with competing GTL processes. Both processes are based on the Fischer-Tropsch (FT) technology, but each uses a different method to produce the syn-gas used as a feed into the FT process and different catalysts in the FT reactor. Syntroleum has perhaps been an open promoter of GTL technology and has presented much of their progress and technology details. ARCO, a major ANS gas owner, has a license agreement with Syntroleum and began operations of a 70-bbl/D pilot plant of the GTL technology in Washington State in 1999. Exxon operated a pilot-scale GTL plant in Baton Rouge, LA from 1990 to 1993 and is studying application of GTL on the North Slope and elsewhere with data from that plant.

\section{Capital Costs}

A feasibility study of applying Exxon's Advanced Gas Conversion for the $21^{\text {st }}$ Century (AGC-21) technology to produce $50,000 \mathrm{~B} / \mathrm{D}$ of middle distillates and other oil based products from 500 million cubic feet of gas was completed jointly by Exxon and Qatar General Petroleum Corp. Capital costs for the project were estimated to be $\$ 1.2$ billion - or $\$ 24,000$ per daily barrel (DBL) of capacity. Other recent reports estimate capital costs for a generic GTL plant to range from $\$ 35,000$ per daily barrel (DBL) down to $\$ 12,000 / \mathrm{DBL}$. Based on these reports, capital costs for a generic GTL plant located on the Gulf Coast are assigned a value of $\$ 24,000 / \mathrm{DBL}$ for this report, equal to the capital costs calculated in the Exxon/Qatar feasibility study.

When considering an installation on the North Slope, a capital cost factor between 1.3 and 2.0 is applied to account for factors intrinsic to the ANS for installations originally cost-estimated for the U.S. Gulf Coast area. A North Slope capital cost factor of 1.5 is used to calculate capital costs in this report. 
Applying the 1.5 North Slope capital cost factor to the base value of $\$ 24,000 / \mathrm{DBL}$ for the generic GTL plant yields capital costs for a North Slope location of \$36,000/DBL.

Costs for first-of-a-kind plants do not often represent the costs of a mature technology. As more plants are built, costs for succeeding plants have historically been reduced. This is called taking advantage of the "learning curve". The cost improvement slope for a large GTL plant is estimated to be -0.74 , which means that for each doubling of cumulative industry production, costs decline to about 74 percent of what they were prior to that doubling. If the GTL plant were constructed in stages, costs of succeeding deployments of the technology would presumably be less than previous versions.

\section{Economic Evaluations}

Evaluating both the Prudhoe Bay field model and the gas project model is necessary to effectively evaluate the scenarios being considered and are tied together by the natural gas transfer price. The transfer price is calculated with the use of the "net back" term. The "net back" refers to the "net' fraction of the gas price sold by the gas project (GTL plant or LNG project) that is returned 'back' to the Prudhoe Bay unit operators as payment for the gas.

\section{Scenarios Evaluated}

Three GTL scenarios, one LNG scenario, and one no-gas-sales scenario were evaluated:

- The No Major Gas Sales scenario consists of continuing with current operations utilizing the natural gas to maximize oil production. Under this scenario, oil production continues until 2025, when the economic limit of the Prudhoe Bay field is reached.

- The Natural Gas Pipeline/LNG Project scenario takes natural gas from Prudhoe Bay beginning in 2005 and reaches a maximum rate of $2.0 \mathrm{Bcf} / \mathrm{D}$ in 2009 . Gas, at a rate of $0.5 \mathrm{Bcf} / \mathrm{D}$, from the Point Thomson unit, which lies 50 miles east of Prudhoe Bay, is also fed into this scenario.

- A Fast-Paced GTL Development scenario consists of constructing a 300,000-B/D GTL plant (2.5 Bcf/D feed rate) on the North Slope to match the timing and volumes proposed in the LNG scenario.

- A Slower-Paced GTL Development scenario consists of a GTL plant construction schedule designed to take advantage of the learning curve associated with implementation of newer technologies. Located on the North Slope, the plant takes gas from Prudhoe Bay at a rate of $0.5 \mathrm{Bcf} / \mathrm{D}$ beginning in 2005. In 2010, a new GTL module of the same capacity is in place; with a new $0.5 \mathrm{Bcf} / \mathrm{D}$ module being constructed every 5 years until a total capacity of 2.5 $\mathrm{Bcf} / \mathrm{D}(300,000 \mathrm{bbl} / \mathrm{D})$ is reached.

- A 300,000-B/D GTL plant (fast-paced) is located in Valdez, AK. This scenario assumes that the natural gas pipeline is built and a tariff is charged to the gas passing through the line. The assumed gas purchase rate is equal to the LNG scenario. A lower capital-cost factor of 1.2 is applied at the Valdez location as opposed to the 1.5 capital cost factor associated with a North Slope location. 


\section{TAPS Tariff Discussion}

The tariff that is charged for transporting liquid through the Trans-Alaska Pipeline System (TAPS) is an important economic parameter. The tariff calculation is based on costs to operate the pipeline, future investments, pipeline profit, and liquid flowrate through the pipeline. TAPS tariffs are a very important part of an analysis of projects that produce liquids from the North Slope of Alaska. The same tariff is applied to all liquids passing through the pipeline; whether it be crude oil, natural gas liquids, or product from a GTL plant. A higher transportation tariff reduces the value of the wellhead product.

GTL liquids increase the flow rate through TAPS, thus lowering the tariff. The LNG option reduces the flow rate through TAPS by decreasing the oil recovery, which increases the TAPS tariff. TAPS tariffs can positively or negatively impact the economic potential of all oil-producing fields on the North Slope, not only the Prudhoe Bay and the Point Thomson units. The benefit of lowering TAPS tariffs because of the addition of GTL products to these other fields is not quantified in this report, but is expected to be significant as a whole.

\section{Economic Results}

A deterministic evaluation of the economic viability of the scenarios outlined above was accomplished by discounted cash flow analysis. (Refer to section 6.2 of the full report for an explanation and discussion of discounted cash flow analysis.) Results of the economic evaluations are best represented by the net present value of the project. The term NPV ${ }_{10}$ represents the net present value evaluated at a discount rate of $10 \%$. Summary Table 1 lists the results of the evaluation for four of the scenarios.

Summary Table 1. Economic evaluations of major gas sales scenarios for the North Slope of Alaska.

\begin{tabular}{|c|c|c|}
\hline Scenario & Entity & $\mathrm{NPV}_{10}(\$$, millions $)$ \\
\hline \multirow{2}{*}{$\begin{array}{l}\text { Major gas sales to gas- } \\
\text { pipeline/LNG-plant }\end{array}$} & $\begin{array}{l}\text { Incremental Prudhoe Bay unit } \\
\text { Gas-pipeline/LNG-plant }\end{array}$ & $\begin{array}{r}589 \\
-2,991\end{array}$ \\
\hline & Total & $-2,402$ \\
\hline \multirow{2}{*}{$\begin{array}{l}\text { Major gas sales to GTL } \\
\text { plant on North Slope (fast- } \\
\text { paced) }\end{array}$} & $\begin{array}{l}\text { Incremental Prudhoe Bay unit } \\
\text { GTL plant }\end{array}$ & $\begin{array}{r}914 \\
-1.297\end{array}$ \\
\hline & Total & -383 \\
\hline \multirow{2}{*}{$\begin{array}{l}\text { Major gas sales to a GTL } \\
\text { plant in southern Alaska } \\
\text { (fast-paced) }\end{array}$} & $\begin{array}{l}\text { Incremental Prudhoe Bay unit } \\
\text { GTL plant }\end{array}$ & $\begin{array}{r}542 \\
-1,908\end{array}$ \\
\hline & Total & $-1,366$ \\
\hline \multirow{2}{*}{$\begin{array}{l}\text { Major gas sales to GTL } \\
\text { plant on North Slope (slow- } \\
\text { paced) }\end{array}$} & $\begin{array}{l}\text { Incremental Prudhoe Bay unit } \\
\text { GTL plant }\end{array}$ & $\begin{array}{r}-113 \\
945\end{array}$ \\
\hline & Total & 832 \\
\hline
\end{tabular}

Of the scenarios analyzed in Summary Table 1, only the slow-paced GTL development scenario has a positive, incremental combined net present value using a discount rate of $10 \%$. However, a negative $\mathrm{NPV}_{10}$ means that its rate of return is less than the discount rate of $10 \%$ and does not necessarily mean that a project loses money.

The gas sales revenues of slow-paced North Slope GTL plant are realized later in the life of this scenario than in the fast-paced GTL scenarios and the LNG scenario, which tends to decrease the net present value of the project. However, the savings in capital costs associated with the "learning curve" that are incorporated into this option outweigh the added discount in revenue caused by delaying the gas sales. 
A fast-paced GTL plant in southern Alaska (Valdez) was compared to the fast-paced GTL plant on the North Slope. Locating the plant at an ice-free port could potentially be economically attractive compared to a North Slope location. Capital costs would be less than the North Slope because of reduced shipping, labor, and materials costs. In the economic evaluation, the capital cost factor was lowered from 1.5 (for the North Slope location) to 1.2. The other major change in evaluations is the additional price of the natural gas at Valdez. The $\$ 6$ billion gas pipeline transporting natural gas from the North Slope to Valdez would still be constructed; adding about $\$ 0.80 / \mathrm{Mcf}$ to the gas feed cost.

\section{Sensitivity Analysis}

There are many sensitivity analyses that could be run on these evaluations. Learning the ramifications of varying input parameters is important to understanding project economics. As this report was primarily concerned with economics of gas-to-liquids technology Alaska, sensitivities were performed only on the GTL plant portion of the total scenarios. The field portion of the scenarios was not further included in the sensitivity analyses.

The object of the analyses was to determine which input parameters cause the greatest effect on project economics. This information is vital in determining those parameters that offer the greatest potential for increasing or decreasing economic viability. These parameters require the most attention and are natural targets for further study by increasing research efforts.

Summary Figure 1 shows results from a sensitivity analysis of the input data for the slow-paced GTL plant development. The numbers on each end of the respective horizontal bars indicate the possible range of the variable in question; while the length of the bar represents that variable's effect economic output. The vertical "most likely" line on the figure indicates the default value for each variable.

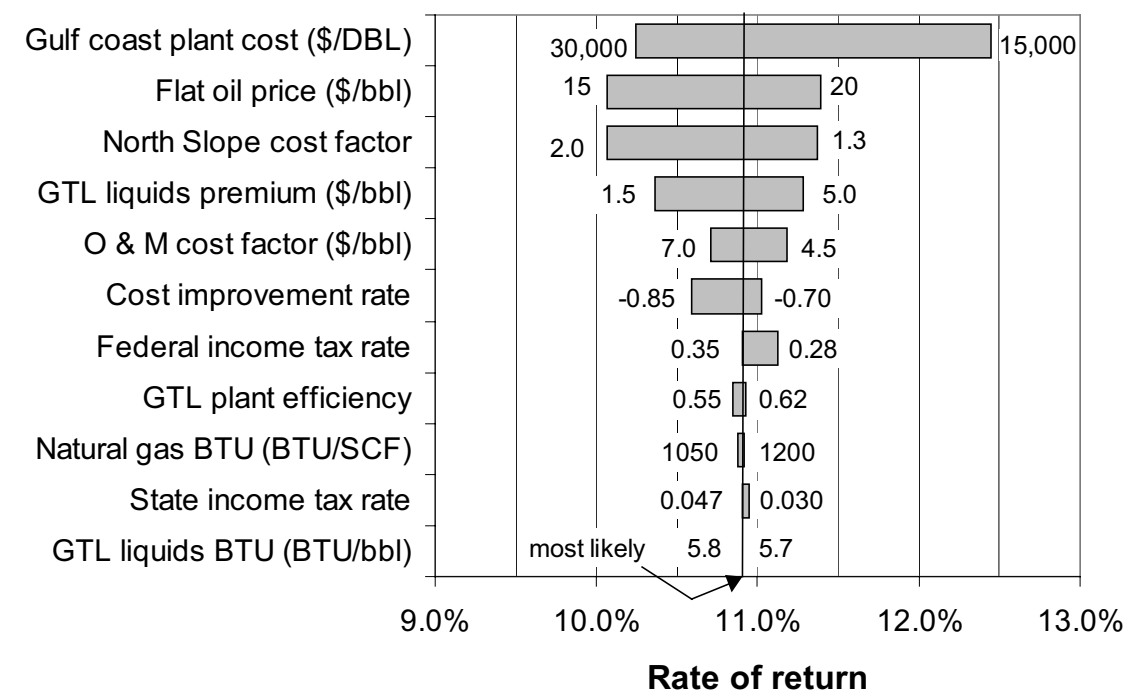

\section{Summary Figure 1 - Sensitivity of input parameters with respect to project economics for the slow-paced GTL plant deployment.}

The four most critical variables, as seen in Summary Figure 1, are the Gulf Coast GTL plant cost, the world oil price, the North Slope cost factor, and the GTL liquids per barrel premium. The ROR using the most likely values for each of the variables is 10.9 percent as shown in Summary Figure 1. 


\section{Monte Carlo analysis}

The Monte Carlo simulation technique permits a "probabilistic analysis" of project economics by applying probability distributions to the input parameters as opposed to the deterministic results tabulated in Summary Table 1. Probabilistic sensitivity analyses do not compute a single result; instead, the outcome is a range of possible results.

Summary Figure 2 is a plot of the probability-of-occurrence versus rate-of-return for a slowpaced GTL plant development on the North Slope. Possible rates of return for a slow-paced GTL development on the North Slope can range from 8.7 percent to 13.1 percent. Applying a 90 percent confidence interval sets the rate or return between 9.8 percent and 11.9 percent. The median value of 10.8 percent indicates that half of the time, a rate of return calculation would return a value of 10.8 percent or greater. The standard deviation is 0.7 percent, which demonstrates that the results are tightly centered on the average of 10.8 percent.

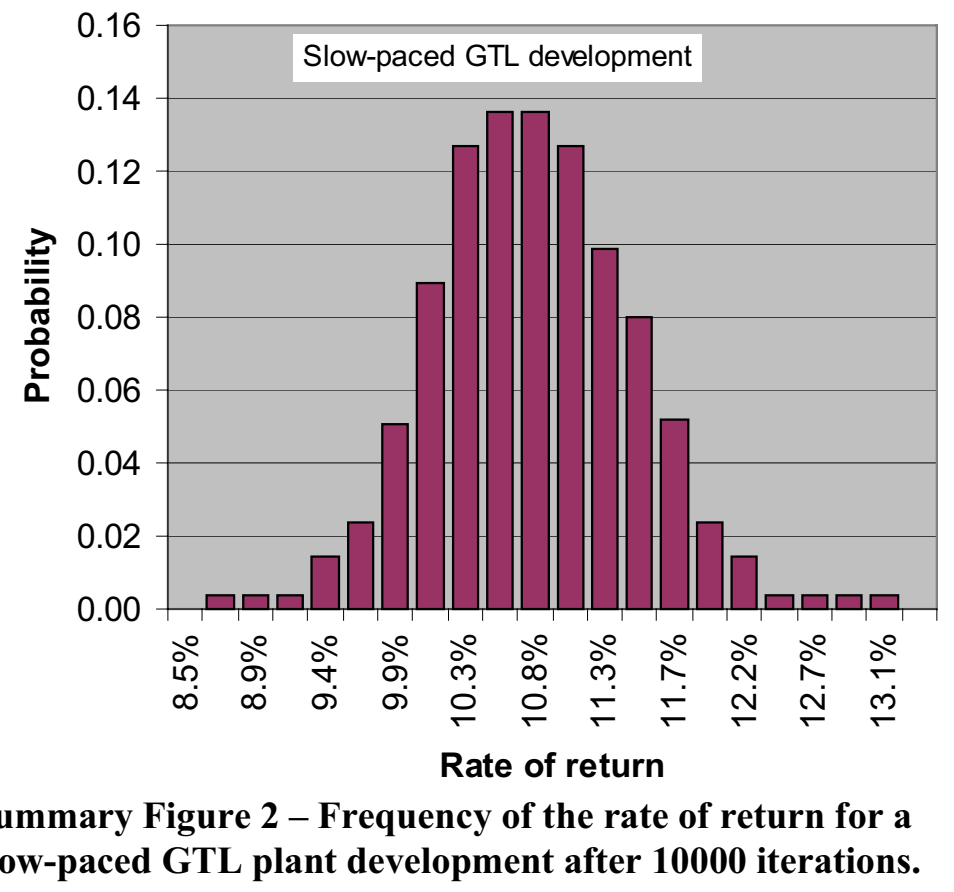

\section{Conclusions}

The purposes of this report were to identify and explore the effect of applying new technology to the economics of a proposed GTL plant, to evaluate the potential of a slower-paced deployment of GTL technology, and to evaluate the effect of GTL plant placement on economics.

Of the gas marketing scenarios evaluated, results indicate that the slow-paced GTL scenario is the only one with a rate of return greater than 10 percent. The other scenarios did not show positive net present values under the economic conditions selected for the simulations. Their rank, in order of net present value, is as follows: slow-paced GTL development, no-major-gas-sales, fast-paced GTL development, fast-paced GTL development in southern Alaska, and finally a gas-pipeline/LNG project.

The slow-paced GTL development would allow cost savings on subsequent expansions. These assumed savings along with the lowering of the transportation tariff combine to distinguish this option for 
marketing the North Slope gas from the other scenarios. Critical variables that need further consideration include the GTL plant cost, the GTL product premium, and operating and maintenance costs. Reducing these costs or increasing the premium could dramatically increase the profitability of the GTL process. Understanding these variables better and reducing their uncertainty would allow a more accurate prediction of economic profitability. Further study of these variables (GTL plant cost, GTL product premium, and $\mathrm{O} \& \mathrm{M}$ costs) is recommended. In addition, a study to quantify the benefit of a tariff reduction caused by a North Slope GTL plant to the economics of other fields (besides Prudhoe Bay) is also recommended. 


\section{ACKNOWLEDGMENTS}

This work was funded by the U.S. Department of Energy's National Energy Technology Laboratory (U.S. DOE-NETL) from the Natural Gas Processing and Utilization division of Emerging Processing Technology Applications managed by Venkat Venkataraman.

The author acknowledges the significant role played by Ralph Avellanet of the U.S. DOE - Fossil Energy and Daniel Driscoll of the U.S. DOENETL in providing programmatic guidance and review of this report. Richard Rice of the Idaho National Engineering \& Environmental Laboratory (INEEL) and manager of Fossil Energy Technologies, provided overall guidance on the scope of the report. Charles Thomas, also of the INEEL and program manager, provided critical review of the report and made contributions to the contents. 


\section{CONTENTS}

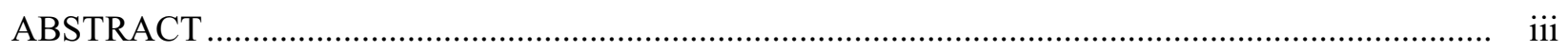

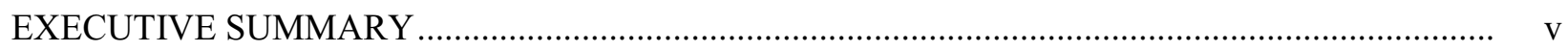

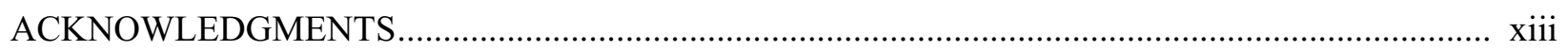

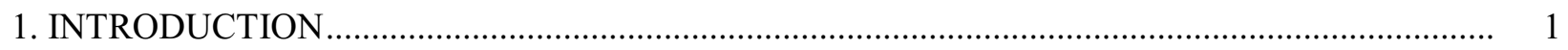

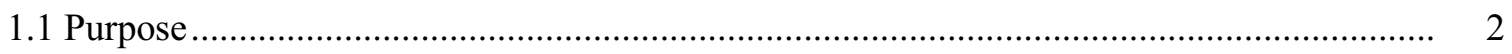

2. OVERVIEW OF NORTH SLOPE FIELDS AND PRODUCTION ............................................... 2

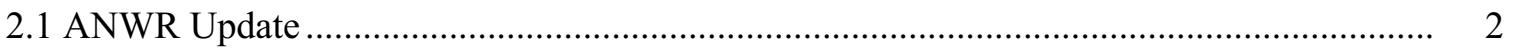

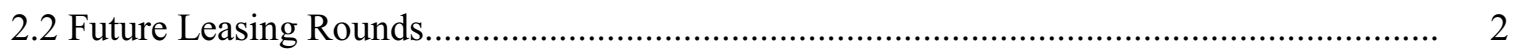

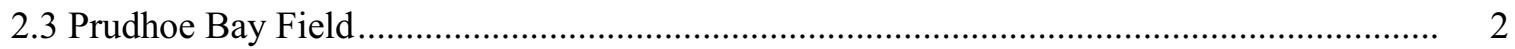

2.3.1 Development Plans..................................................................................... 3

2.3.2 Production Forecasts and Recoverable Oil …............................................... 3

2.3.3 Prudhoe Bay Investments........................................................................... 4

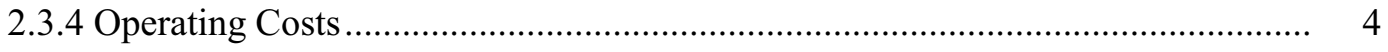

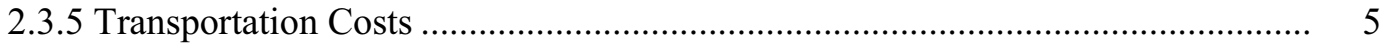

2.3.6 Lost Oil Recovery Due to Major Gas Sales ................................................. 5

2.3.7 Gas Production from Prudhoe Bay ............................................................ 6

3. CURRENT STATUS OF GAS COMMERCIALIZATION EFFORTS ….................................... 6

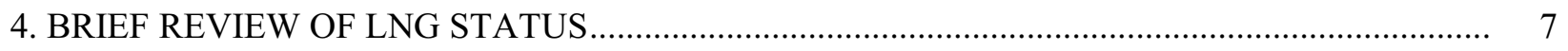

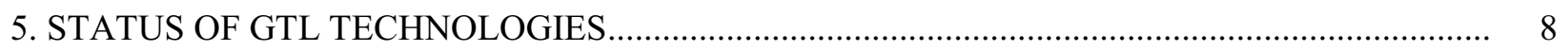

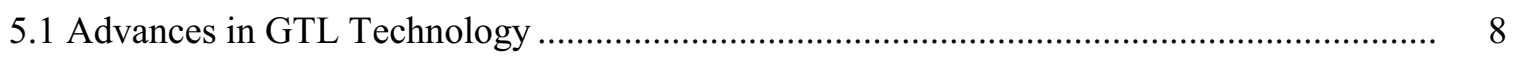

5.2 Pipeline Transport of the GTL Product ..................................................................... 9

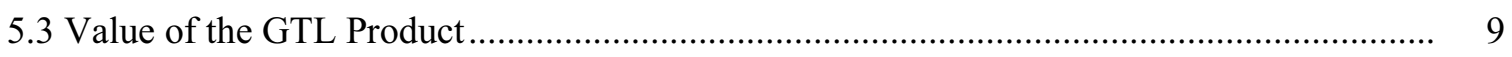

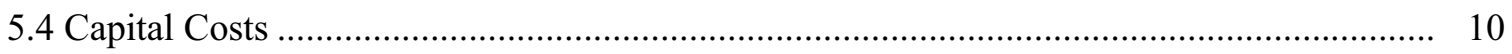

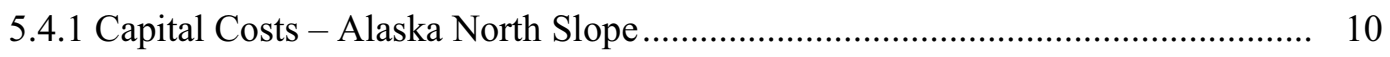

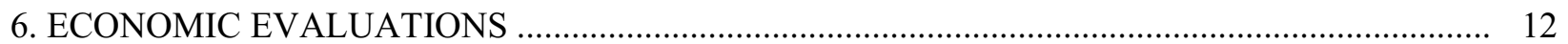




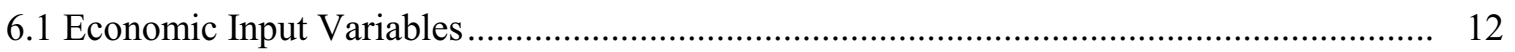

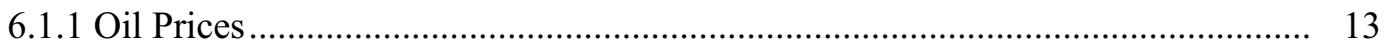

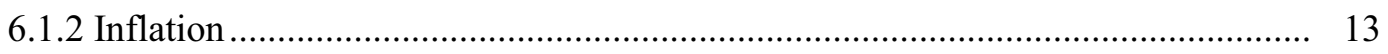

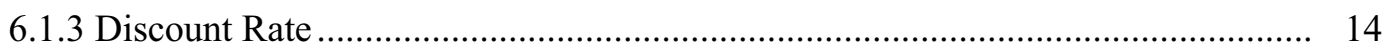

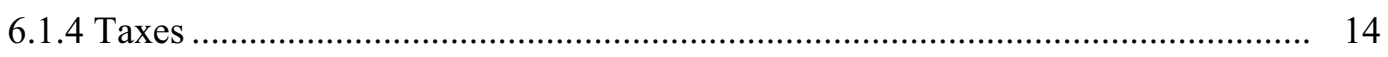

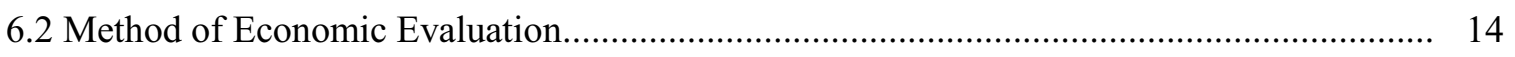

6.2.1 Relationship between Prudhoe Bay and Gas Project .................................... 16

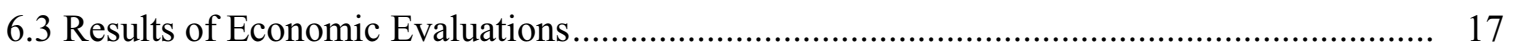

6.3.1 Scenarios Evaluated .......................................................................... 17

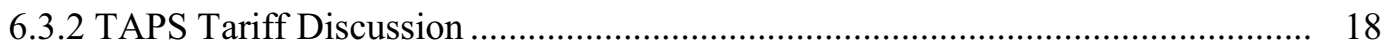

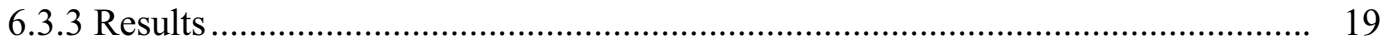

6.3.4 Discussion of Results .............................................................................. 20

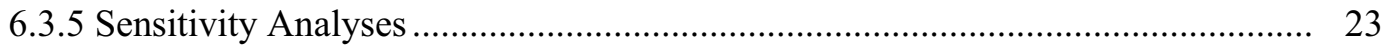

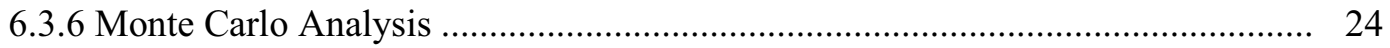

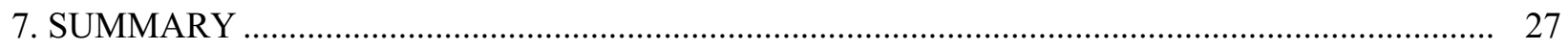

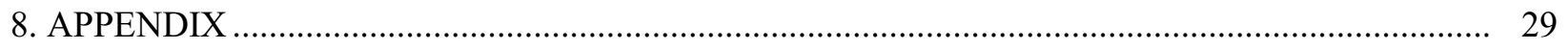

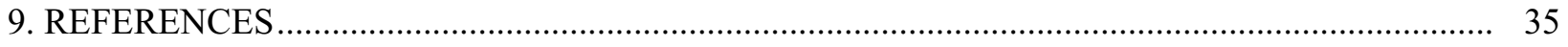

FIGURES

Figure 1. Well penetrations in the Prudhoe Bay field ................................................................ 3

Figure 2. Oil production forecast for the Prudhoe Bay unit and the entire North Slope .................... 4

Figure 3. Water-cut curve used to calculate operating costs for the Prudhoe Bay unit ...................... 4

Figure 4. TAPS tariff forecast for scenario with no major gas sales ........................................... 5

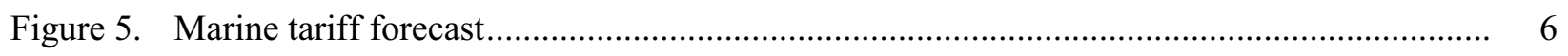

Figure 6. Historical and forecast world oil prices. Data from Energy Information Admini-

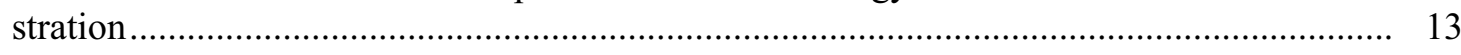

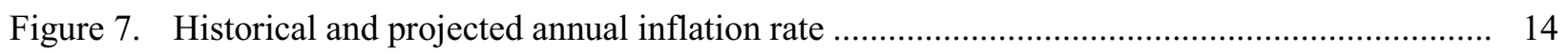


Figure 8. Flow chart describing economic evaluations and relationships between data files and models

Figure 9. TAPS tariff forecasts in $1998 \$$ for four scenarios

Figure 10. NPV calculations for gas sales to LNG scenario.

Figure 11. NPV calculations for gas sales to GTL plant (fast-paced) scenario

Figure 12. NPV calculations for gas sales to GTL plant (slow-paced) scenario

Figure 13. NPV calculations for gas sales to a GTL plant (fast-paced) in southern Alaska.

Figure 14. Sensitivity of input parameters with respect to project economics for the slowpaced, staged GTL development scenario.

Figure 15. Example of a triangular distribution of an input variable for Monte Carlo analysis.

Figure 16. Frequency plot of the rate of return for a slow-paced GTL plant development after 10000 iterations.

Figure 17. Cumulative probability of occurrence for the rate of return of a slow-paced GTL plant development

\section{TABLES}

Table 1. Economic evaluations of major gas sales scenarios for the North Slope of Alaska.

Table 2. Minimum, maximum, and most likely values for triangular distributions used in Monte Carlo analysis. 


\section{Options for Gas-to-Liquids Technology in Alaska}

\section{INTRODUCTION}

The Alaska North Slope (ANS) holds a vast resource of natural gas that could be of great benefit not only to Alaska, but to the whole United States and other countries provided an economical scheme could be developed to transport the gas from the North Slope. Currently, the produced gas is being reinjected to effectively increase oil recovery, but will have greater economic benefit if able to be transported from the North Slope to world markets as oil production wanes in the future. The Prudhoe Bay field contains the largest portion of the discovered natural gas on the North Slope or about 21.8 Tcf of natural gas available for sale after $\mathrm{CO}_{2}$ removal and satisfying power requirements and other North Slope use.

This report focuses on the economics of applying technology that converts natural gas to highquality liquid transportation fuels as a method to market the North Slope gas. In 1996, the Idaho National Engineering \& Environmental Laboratory (INEEL) published a report for the U.S. Department of Energy entitled "Economics of Alaska North Slope Gas Utilization Options," by Thomas, et al. ${ }^{1}$ In that report, which will be referred to as the 1996 DOE report, three gas marketing scenarios were compared. Scenario 1 was to continue oil production operations with no major natural gas sales. Scenario 2 was to construct an 800-mile natural gas pipeline paralleling the trans-Alaska oil pipeline system (TAPS) and convert the natural gas to liquefied natural gas (LNG) at or near Valdez, AK; marketing the LNG in the Asian Pacific Rim via LNG tankers. Scenario 3 was to build a gas-to-liquids (GTL) plant on the North Slope that would convert an equivalent quantity of natural gas into a stable, liquid fuel that would then be transported through TAPS - marketing the GTL product on the U.S. West Coast as transportation fuel.

Since 1996, new information regarding GTL technology has been released to the public that appears to enhance the economic viability of the GTL project option for marketing ANS gas and was not incorporated in the 1996 DOE study. The objective of this current report is to expand the work completed in the 1996 DOE report and to conduct a focussed, follow-up investigation to that work. Specifically, to incorporate new information regarding GTL technology, and to look at the development-pace and placement of a GTL project. It has been argued that by constructing a large GTL facility in stages, one could take advantage of the learning curve associated with new technologies and reduce costs of subsequent stages. These cost savings could offset revenue losses associated with the time-value of money.

This report relies on portions of the work performed in the 1996 DOE report. For example, the Prudhoe Bay field analysis, the TAPS tariff calculation methodology, and the framework for the economic analysis were updated from the 1996 DOE report.

In performing an economic analysis of a gas-marketing scenario involving natural gas from the ANS, it is necessary to understand the interrelationship between gas sales and oil revenue. For example, the quantity, timing, and pace of major gas sales can have a major impact on the oil recovery of the Prudhoe Bay field. The Prudhoe Bay natural gas is currently being used to enhance oil recovery from the field. If that gas is sold, it becomes unavailable for use in enhanced oil recovery operations, and although selling the gas may generate revenue, its use may reduce the revenue generated from oil operations. The economic evaluation of a gas-marketing scenario, therefore, must include an analysis of the entire producing field - both oil and gas revenues - as well as an analysis of the operations of the gas-marketing scheme. 


\subsection{Purpose}

The purposes of this study are:

1) To apply technical advances to the GTL scenario evaluated in the 1996 DOE report to determine the effects new technology and knowledge have on the economics of the GTL project.

2) To evaluate the potential economic impact of a slower-paced, staged deployment of GTL technology on the North Slope; thus taking advantage of experience and technological improvements in later plant expansions.

3) To evaluate the concurrent development of both the LNG and GTL projects; with the GTL plant located in southern Alaska at the gas pipeline terminus.

\section{OVERVIEW OF NORTH SLOPE FIELDS AND PRODUCTION}

Oil production is projected to increase from the North Slope within the next five years, reversing a seven-year stretch of continual yearly declines. The increase is expected to be fueled by production from six new fields - Alpine, Badami, Northstar, Liberty, Tarn, and PBU satellites; and by increased production from Schrader Bluff and West Sak. However, development has been slowed because of depressed oil prices in 1998 and early 1999.

\subsection{ANWR Update ${ }^{2}$}

The U.S. Geological Survey's (USGS) mid-range estimate for oil-in-place under the 1002 area in the Arctic National Wildlife Refuge was increased in May 1998 to 20.7 billion barrels, up from 13.8 billion barrels estimated in 1987. The mid-range estimate of recoverable oil from this area was raised to 10.3 billion barrels.

Several developments have influenced the understanding of oil potential in the area. Exploratory wells, such as those recently drilled in the Sourdough area, ${ }^{3}$ have provided new geologic data for the USGS assessment. Seismic information from older wells drilled in the area was given to the USGS. Advances in processing older 2-D seismic data have been developed and were used by the assessment team. Finally, cost-cutting and technological advances have reduced the minimum field size for stand-alone economic development from 400 to 500 million barrels down to 100 million barrels.

\subsection{Future Leasing Rounds}

The U.S. Department of Interior (DOI) announced in 1998 that 4 million acres in the northeast corner of the National Petroleum Reserve in Alaska - just to the west of the Alpine field, ARCO's discovery on the Colville River delta - would be available for leasing. The Interior Department estimates the reserve's northeast quadrant holds from 500 million barrels to 2.2 billion barrels of recoverable crude oil. $^{4}$

\subsection{Prudhoe Bay Field}

The Prudhoe Bay field is the largest field in North America and lies on the Arctic coastline about 200 miles east of Point Barrow. There were about 23 billion barrels of oil originally in place (OOIP) and $46 \mathrm{Tcf}$ of gas originally in place. Ultimate oil-recovery estimates have been increasing over the years as 
more is learned about the field and as enhanced oil recovery techniques and cost reduction efforts continue to improve.

\subsubsection{Development Plans}

As of early 1998, development plans indicated that 105 penetrations were planned for the Prudhoe Bay field in 1998 - 51 coiled tubing sidetracks, 33 will be conventional sidetracks, and 21 new wells. ${ }^{5}$ In 1999 and 2000, 115 penetrations are planned per year - 61 coiled tubing sidetracks, 32 conventional sidetracks, and 22 new wells. Development plans for years 2001 to 2005 were extrapolated from historical data to 50 penetrations per year and the same ratio of penetration types was assumed. ${ }^{6}$ No new well penetrations were assumed beyond the year 2005 as shown in Fig. 1.

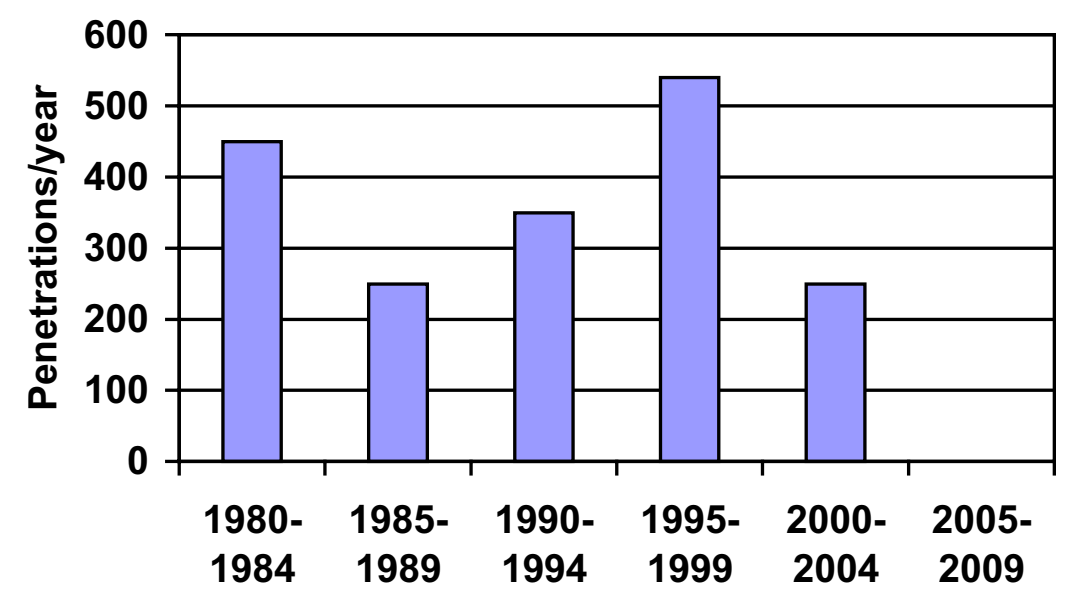

Figure 1 - Well penetrations in the Prudhoe Bay field.

\subsubsection{Production Forecasts and Recoverable Oil}

Production curves in this report are forecasted through 2025 for the entire North Slope as well as for the Prudhoe Bay unit. Forecasts were taken from data supplied by the Alaska Division of Natural Resources - Division of Oil and Gas (ADNR-DOG), which forecasts only through the year 2020. ${ }^{7}$ Oil production for the Prudhoe Bay field in 2020 is projected to be equal to $223 \mathrm{Mbbl} / \mathrm{D}$, which is greater than the assumed minimum rate of $160 \mathrm{Mbbl} / \mathrm{D}$ necessary for economic viability of the field. ${ }^{\mathrm{a}}$ This indicates that more oil will be produced from Prudhoe Bay beyond 2020. An exponential decline rate of $0.054 \mathrm{yr}^{-1}$ was calculated from data between 2005 and 2020 and was applied to a five-year extrapolation of the ADNR-DOG forecast, which extended the forecast to 2025 as shown in Fig 2. Extending Prudhoe Bay production until 2025 brings the production rate down to $169 \mathrm{Mbbl} / \mathrm{D}$, which is in line with industry's assumed minimum rate for the field.

Ultimate recovery from the Prudhoe Bay unit (PBU) was estimated to be 13.0 billion barrels in the 1996 DOE report. However, Platt's Oilgram has reported that ultimate recovery could be higher than 13 billion barrels. ${ }^{8}$ In addition, according to the 1998 ADNR-DOG oil production forecast, the ultimate recovery from PBU is expected to be 13.32 billion barrels. By extrapolating the forecast data another five years the expected ultimate recovery from PBU used in this study was increased to 13.67 billion barrels.

\footnotetext{
${ }^{\text {a }}$ Personal communication with industry representatives, March 1998.
} 


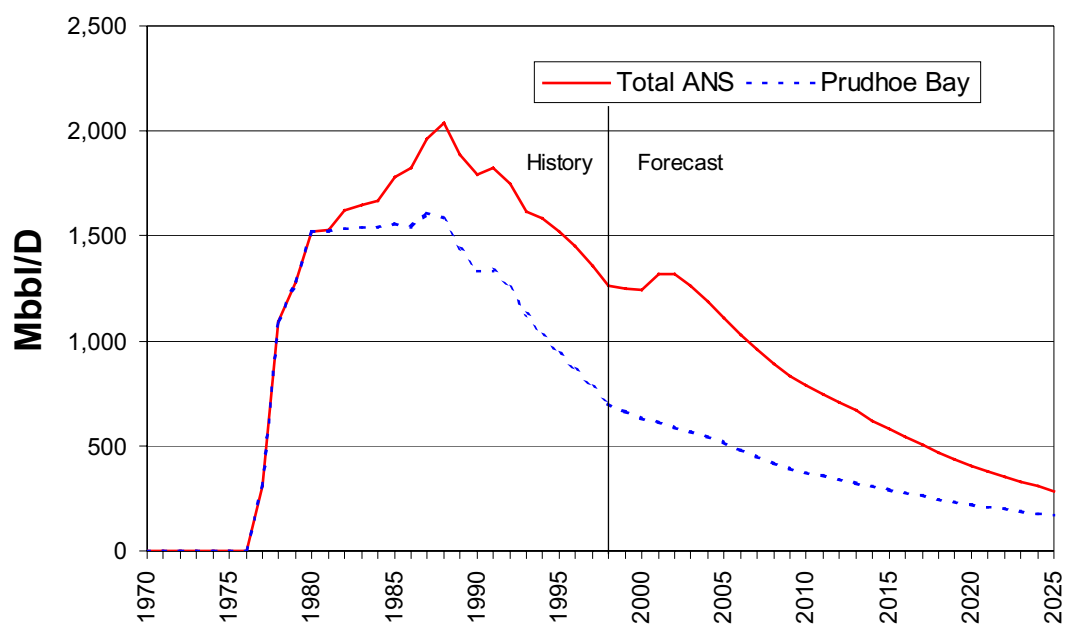

Figure 2 - Oil production forecast for the Prudhoe Bay unit and the entire North Slope.

\subsubsection{Prudhoe Bay Investments}

Estimates of future investments were based on drilling plans; current drilling costs; and planned surface facilities costs (see section 2.3.1). The cost of the average well penetration has been reduced from the $\$ 2.2$ million used in the 1996 DOE report to \$1.5 million. ${ }^{9}$ Investment for expansion of the ongoing miscible injectant project is expected to total $\$ 165$ million and is scheduled to be completed by 2000 .

\subsubsection{Operating Costs}

Operating costs are estimated based on a cost per barrel of total fluid (BTF) produced. The forecast for future total fluid produced was obtained by plotting the water cut - obtained from historical Prudhoe Bay production data - versus percent recovery and extrapolating to $75 \%$ water cut at $100 \%$ of ultimate recovery, as shown in Fig. 3. The water cut is defined as the fraction of the total produced fluid that is water. The operating cost factor of $\$ 1.180 / \mathrm{BTF}$ used in this study was inflated to $1998 \$$ from the oper-

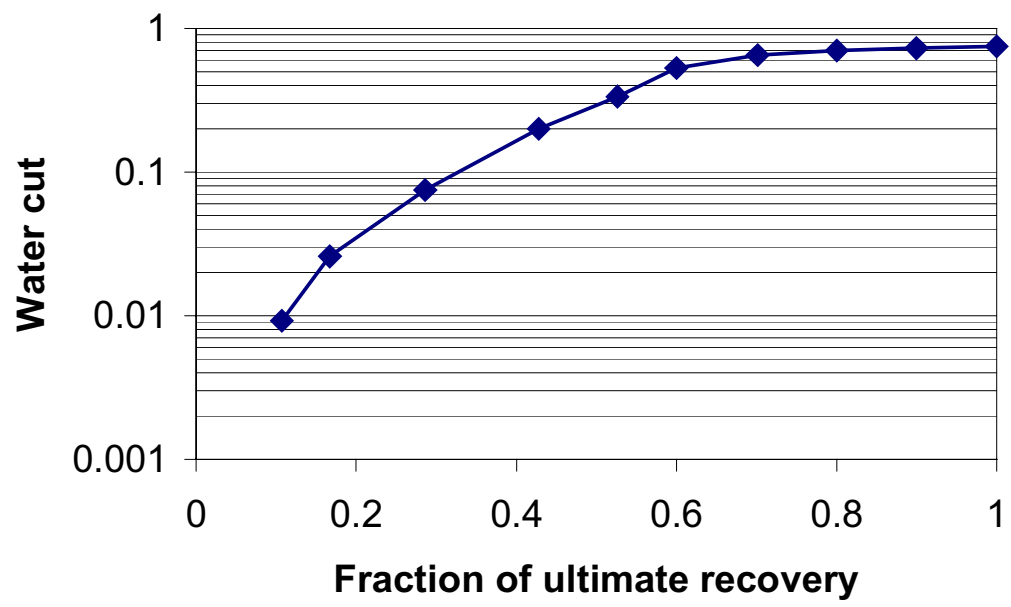

Figure 3 - Water-cut curve used to calculate operating costs for the Prudhoe Bay unit. 
ating-cost factor used in the 1996 DOE report.

\subsubsection{Transportation Costs}

Transportation costs are the sum of costs associated with transporting the oil through TAPS and those associated with shipping the oil from Valdez to world markets. Both costs are calculated as tariffs: a TAPS tariff and a marine tariff.

2.3.5.1 TAPS Tariff. The TAPS tariff used in this report uses the same methodology as in the 1996 DOE report; however, the values of input variables have been updated to reflect 1998 values and forecasts of expenditures. Yearly tariffs used in the economic evaluations are based on total liquid throughput, pipeline operating expenses, and allowable margin. The calculated TAPS tariff for scenario 1 (no future major gas sales) is shown in Fig. 4. TAPS tariff forecasts for other scenarios and their importance in economic evaluations are discussed in section 6.3.2.

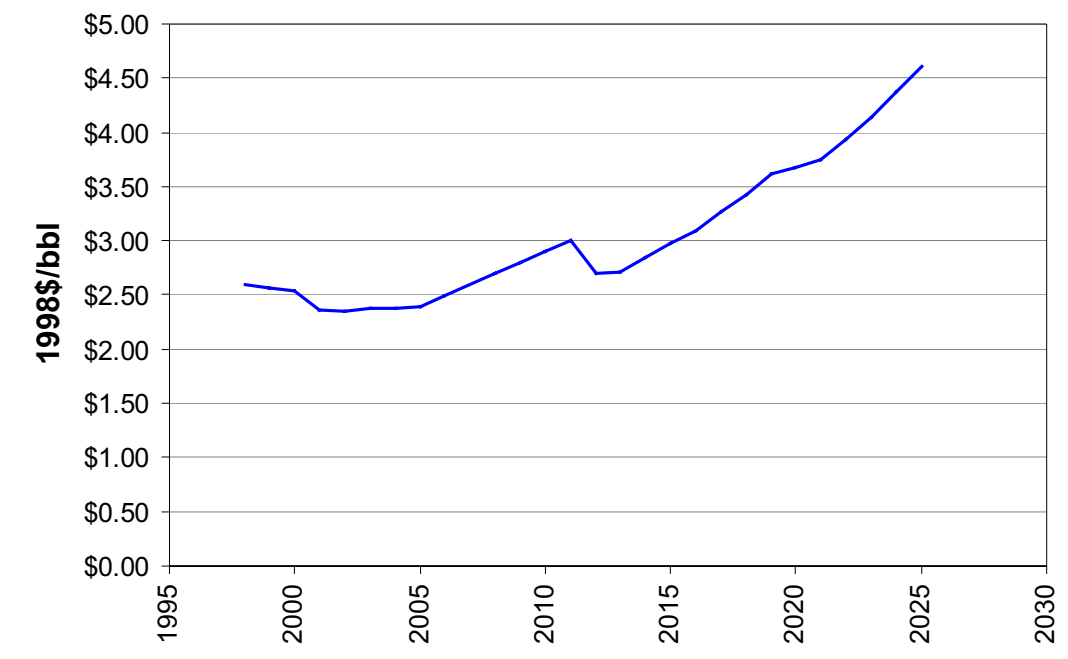

Figure 4 - TAPS tariff forecast for scenario with no major gas sales.

2.3.5.2 Marine Tariff. The marine tariff values used in transportation calculations are taken from the Alaska Department of Revenue, Fall 1997 Revenue Sources Book, Table 8, and average about \$1.80/bbl $(1998 \$)$ in the future. Forecasted values are shown in Fig. 5.

\subsubsection{Lost Oil Recovery due to Major Gas Sales}

Oil recovery can be affected by marketing the produced natural gas off the North Slope as opposed to using it to enhance oil production according to the $1996 \mathrm{DOE}$ report. If major gas sales begin in 2005, 400 million bbl of oil is assumed lost. This would occur because of the unavailability of the gas for use in highly effective enhanced oil recovery programs such as pressure maintenance, miscible injectant flooding, and water-alternating-gas programs. Later major gas sales would have a lesser impact on oil recovery simply because there would be less oil available to recover. Major gas sales beginning in 2010 are assumed to cause a loss of 100 million bbl; and gas sales beginning in 2015 would have a negligible effect on oil recovery. 


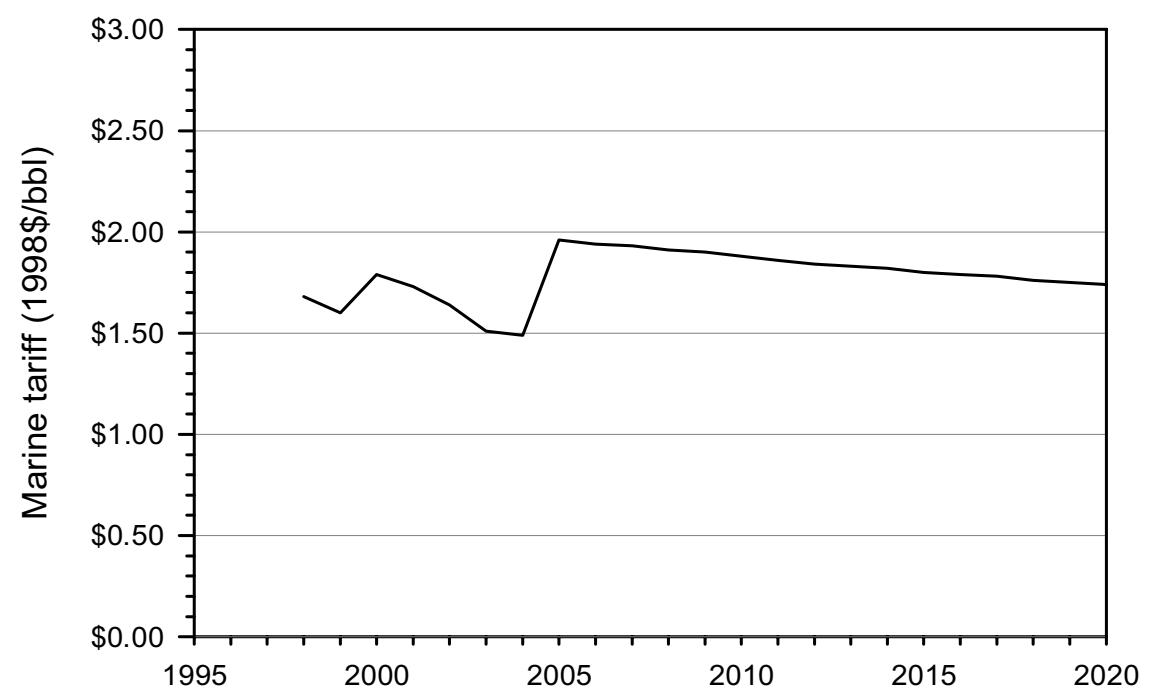

Figure 5 - Marine tariff forecast.

\subsubsection{Gas Production from Prudhoe Bay}

Of the $46 \mathrm{Tcf}$ of natural gas originally in place in the Prudhoe Bay field, 30 Tcf resides in the gas cap and $16 \mathrm{Tcf}$ lies within the oil rim. ${ }^{1}$ Natural gas (containing $12 \% \mathrm{CO}_{2}$ ) is currently being produced at a rate of about $8 \mathrm{Bcf} / \mathrm{D}$ from $\mathrm{PBU}$ as part of oil production operations. The heavier components of the produced gas are removed and shipped to market as natural gas liquids (NGL) or used as miscible injectant to recover crude oil. Some of the lean gas is used as fuel and the remainder (about $7 \mathrm{Bcf} / \mathrm{D}$ ) is reinjected into the gas cap. Of the original $46 \mathrm{Tcf}$ in place, over $2.8 \mathrm{Tcf}$ have been used as fuel for heating or sold as NGL to date.

A recovery factor of 80 percent is assumed to apply to the gas in the gas cap and a recovery factor of 60 percent to the gas in the oil rim. Recoverable gas in the gas cap is then 24 Tcf and oil rim gas is 9.6 $\mathrm{Tcf}$ for a total of $33.6 \mathrm{Tcf}$ of recoverable gas. A total of $8.8 \mathrm{Tcf}$ are expected to be unavailable for sale due to total lease use, local sales, NGL sales, and shrinkage, which leaves net gas (including $\mathrm{CO}_{2}$ ) of 24.8 Tcf. Removing the $\mathrm{CO}_{2}$ lowers the net gas available for sale from PBU to $21.8 \mathrm{Tcf}$.

\section{CURRENT STATUS OF GAS COMMERCIALIZATION EFFORTS}

Commercializing or marketing the natural gas residing on the North Slope has been a major goal of the field operators since the Prudhoe Bay field was first unitized. Recently, efforts to arrive at an economic marketing plan have intensified. Two scenarios receiving the most consideration are an LNG option and a GTL option. The LNG scenario involves constructing an 800-mile gas pipeline, an LNG facility in Valdez, AK, and shipping LNG to Asia via LNG tankers. The GTL scenario involves constructing a GTL plant on the North Slope and transporting the GTL product through TAPS and to market via regular oil tankers. However, neither scenario has been selected exclusively as the preferred method to market the large gas resource on the North Slope.

In January 1998, the Alaska Department of Natural Resources released a report entitled Alaska North Slope Gas Commercialization Team - Report to the Governor. ${ }^{10}$ This report discussed ways the State of Alaska and the federal government could improve the economic feasibility and competitiveness of a North Slope gas project and focused almost exclusively on the LNG option. It addressed ways the 
state could lower taxes or change the tax structure to increase the economic viability of a North Slope gas project.

In letters attached to the Report to the Governor, ARCO, BP, and Exxon commented on the contents of the report and general gas-commercialization efforts. ARCO expressed concern that despite the State's efforts, an LNG project may still be undercut by higher rate-of-return projects from around the world to provide anticipated Far East markets. BP encouraged the state to address the fiscal and regulatory system with respect to the emerging GTL technology as well. Exxon urged the State to maintain adequate flexibility to address the special needs of any stranded gas project, whether it be LNG or GTL.

ARCO has constructed a GTL pilot plant at Cherry Point, its refinery in Washington State, where it is conducting research on catalysts and reactor design technology and employs a GTL approach that uses air instead of oxygen to generate syn-gas. Catalyst selection and process reactor design changes are being studied to help reduce the costs of GTL technology. ${ }^{11}$

In July 1998, Exxon Corporation formed a study group to look at the potential for a gas-to-liquids plant on Alaska's North Slope. Although Exxon considers liquefied natural gas as the first option for Alaska's Arctic gas reserves, the company believes there is enough gas on the North Slope for both an LNG and a GTL project. ${ }^{12}$

Yukon Pacific Corporation (CSX Corporation) reported in August 1998 that the cost to construct the 800 -mile gas pipeline could be reduced by $\$ 1$ to $\$ 2$ billion if the latest pipeline engineering technology was incorporated in the line's construction cost estimates. ${ }^{13}$

Also in August 1998, it was announced that a group of five companies signed the Alaska North Slope (ANS) Gas Project Sponsor Agreement. ${ }^{14}$ The agreement is meant to identify a viable project for transporting a portion of the vast ANS stranded gas reserves to markets in East Asia in the form of liquefied natural gas. The initial phase of the agreement will cover a four-year period costing approximately $\$ 100$ million, will focus primarily on defining costs and minimizing economic uncertainty, and will address possible pipeline routes, engineering, permitting, and commercial work of all aspects of the project. Companies involved in the agreement included ARCO Alaska, Inc. 37\%, Foothills Pipe Lines Ltd. 22\%, Marubeni Corporation 17\%, Phillips Petroleum Company 12\%, and CSX Corporation 12\%. However, in August 1999, CSX withdrew from the group, opting to focus solely on a preferred gas pipeline to Valdez route.

\section{BRIEF REVIEW OF LNG STATUS}

In 1997, total world LNG imports were 81.759 million tons, of which, 61.728 million tons went to East Asia, or $75 \%$ of world LNG imports. Japan imported 47.106 million tons, Korea imported 11.457 million tons, and Taiwan imported 3.165 million tons in 1997. ${ }^{15}$ Japan imports LNG from the U.S.A. (Alaska), Brunei, Abu Dhabi, Indonesia, Malaysia, Australia, and Qatar. ${ }^{16}$

LNG demand in East Asia is expected to rise to 80 million tons in 2000, 100 million tons in 2005, and 130 million tons in 2010. ${ }^{16}$ There are many new potential LNG supply sources competing to fill this growing market. These include Qatar, Oman, and Yemen in the Middle East; Malaysia and Indonesia in Asia; the north and northwest areas of Australia; and Sakhalin and Alaska in the north Pacific. ${ }^{16}$ Indonesia's Tangguh Project boosted proved reserves, critical to the formation of an LNG project, dramatically from $6.3 \mathrm{Tcf}$ reported in 1997 to $14.4 \mathrm{Tcf}$ as of July 31, 1998. ${ }^{17}$ Whether an ANS gas project can compete with these or other new sources of LNG remains to be seen. 
The state of Alaska passed the Alaska Stranded Gas Development Act in early 1998 that authorized the state to negotiate payments from sponsors of the proposed gas line in lieu of taxes that otherwise would be imposed. These taxes include state and local property taxes, sales and use taxes, production or severance tax, and state corporate income tax. In addition, it provides municipalities the option of an equity interest in the project in lieu of taxes. The Act was written exclusively for the gas pipeline/LNG option, excluding the potential gas-to-liquids scenario for marketing ANS gas. ${ }^{18}$

According to a report by Pedro van Meurs, changes in the federal tax structure and reductions in capital costs are more important to the economics of a project than changes in state tax structure. ${ }^{19} \mathrm{Nev}-$ ertheless, the state tax restructuring accomplished by the State's Stranded Gas Act would help the economics of the project, especially if combined with federal tax changes and reductions in capital costs. ${ }^{20}$

\section{STATUS OF GTL TECHNOLOGIES}

The GTL process evaluated in the1996 DOE report was based on the Shell middle-distillate synthesis technology as discussed in the J. Eilers et al. paper: "The Shell Middle Distillate Synthesis Process (SMDS)." ${ }^{21}$ This paper was written before Shell's Bintulu, Malaysia plant began operation in 1992. Since that time, several competing technologies have been brought to light that could significantly improve the economics of GTL technology.

\subsection{Advances in GTL Technology}

The Alaska Department of Revenue compiled a brief comparison of six gas-to-liquid technologies:

1) A basic Fischer-Tropsch (F-T) technology,

2) Sasol's F-T technology,

3) Exxon's AGC-21,

4) BP's compact steam reformer,

5) Syntroleum's diluted nitrogen technology, and

6) An F-T process using DOE's Ceramic Membrane.

This comparison (shown in the Appendix) gives capital costs per barrel of liquid product and O\&M costs per barrel of liquid product. The values given have been generated from publicly available data, but not necessarily from existing plants. The Appendix compares not only costs, but explains each process and notes differences in technology and approach.

Syntroleum has been a vigorous promoter of GTL technology and has presented some details of their progress and technology. It has taken the approach of using air instead of pure oxygen in the syngas generation step of the GTL process. In February 1998, SLH Corp, Syntroleum's parent corporation announced plans to build an 8,000 B/D gas-to-liquids plant in Sweetwater County, Wyoming in conjunction with Enron Corp. ${ }^{22}$ ARCO has a license agreement with Syntroleum and began operation of a pilot plant of the GTL technology in Washington State in 1999.

Exxon operated a pilot-scale plant in Baton Rouge, LA from 1990 to 1993 and is studying application of GTL on the North Slope with data from that plant. In October in 1996, the Wall Street Journal reported that Exxon was holding talks with Qatar to build a GTL plant utilizing that country's vast natural gas resources. Although the project apparently fell through, a feasibility study of applying Exxon's Advanced Gas Conversion for the $21^{\text {st }}$ Century (AGC-21) technology was completed jointly by Exxon and Qatar General Petroleum Corp. The plant was to produce 50,000 B/D of middle distillates and other oil based products from 500 million cubic feet of gas per day. Capital costs for the projects were estimated 
to be $\$ 1.2$ billion - or $\$ 24,000$ per daily barrel (DBL) of capacity. Exxon published limited details on its technology at industry meetings in 1994 and again in $1995^{23,24}$

The Alaska Department of Revenue's brief comparison of six gas-to-liquid technologies is the sole source of information located for this report that gives details on the GTL process being explored by BP Exploration (Alaska).

\subsection{Pipeline Transport of the GTL Product}

Discussions with the Alyeska Pipeline Company were held in March of 1998 on the subject of transporting the GTL product through the trans-Alaska pipeline system (TAPS). The GTL product could either be slugged down the pipeline or shipped concurrently with the crude oil (mixed). Alyeska has done some calculations on how best to batch the GTL product through the pipeline, if the intent was to slug the product to avoid mixing with crude oil. Alyeska indicated that at high pipeline flow rates (around 1000 $\mathrm{Mbbl} / \mathrm{D}$ or above), the mixing zone between the GTL product and the crude oil would be sufficiently small to minimize contamination of the GTL product. However, at lower flow rates, a pigging system could be used to mechanically separate the two fluids to minimize mixing during pipeline transport. Alyeska indicated that they have not publicly released any supportive documentation, but if there were a high probability of a GTL project on the North Slope, a report or paper would be issued.

\subsection{Value of the GTL Product}

The price of gasoline has averaged $\$ 8 / \mathrm{bbl}$ over the price of crude oil and diesel has averaged $\$ 6 / \mathrm{bbl}$ over crude oil over the past 10 years. ${ }^{1}$ The product from Exxon's AGC-21 process produces a refinery feedstock free of most of the impurities found in conventional crude oil; being totally free of sulfur, nitrogen, nickel, vanadium, asphaltenes, multi-ring aromatics, and salt. ${ }^{23}$ The product-upgrading step offers a flexible petroleum-product slate. When operated at relatively low severity, it maximizes feed to refinery catalytic cracking and lubricant production. At higher severity, all catalytic cracker feed boiling material can be eliminated, yielding up to $70 \%$ of the liquid product as jet and diesel fuel, with the remainder being naphtha. The process is not suitable for the direct production of gasoline; the major impact of this process is on the distillate (heating oil, jet fuel, and diesel) manufacturing industry, the petrochemical industry, and the lube industry. ${ }^{25}$

Because the GTL product is a high-quality refinery feedstock, it must pass through a refinery before becoming an end-use product such as diesel fuel or gasoline. ${ }^{23}$ To arrive at an upper bound for the product value, we assume the GTL product is batched through the pipeline and is input into a refinery as a clean feedstock that produces equal amounts of gasoline and diesel. The prices for diesel and gasoline have historically been about $\$ 6.00 / \mathrm{bbl}$ and $\$ 8.00 / \mathrm{bbl}$ over world crude oil price respectively; therefore, the average premium of the refinery output would be $\$ 7.00 / \mathrm{bbl}$ over the world oil price. By subtracting an assumed gross refinery margin of $\$ 2.00 / \mathrm{bbl}^{26}$ from the output price, the GTL product premium becomes $\$ 5.00 / \mathrm{bbl}$ over the world crude oil price.

The above methodology for obtaining an upper bound for the value of the GTL product ignores possible added value based on future sulfur regulations. Because the GTL product is totally free of sulfur, nitrogen, nickel, vanadium, asphaltenes, multi-ring aromatics, and salt, the gasoline and diesel produced from the GTL feedstock could be of greater value than gasoline and diesel produced from conventional crude oil. Therefore, the premium could conceivably be higher than $\$ 5 / \mathrm{bbl}$.

To obtain a lower bound of the product value, it was assumed that the product is of lesser quality and is shipped together with the crude oil through TAPS and then refined. In this case, diesel or gasoline 
may not be the primary product and additional refining may be necessary. A lower bound for the GTL product premium could be as low as $\$ 1.50 / \mathrm{bbl}$ over the average price of world crude oil.

The GTL product's actual value most likely lies somewhere between $\$ 1.50$ and $\$ 5.00$ over the world crude oil price. For this analysis, $\$ 3.50 / \mathrm{bbl}$ is the assumed GTL product premium over world crude oil prices.

\subsection{Capital Costs}

In November of 1996, Salomon Brothers published a report on recent gas-to-liquids advances. ${ }^{27}$ The majority of their report focussed on Exxon's process and Syntroleum's process. The report states that the capital cost of a GTL plant is roughly estimated at between $\$ 25,000$ per daily barrel (DBL) capacity and $\$ 35,000 / \mathrm{DBL}$, but suggest capital costs as low as $\$ 13,000 / \mathrm{DBL}$ are possible. Capital costs for Exxon's 50,000-B/D Qatar project were estimated to be $\$ 24,000$ per daily barrel (DBL) of capacity.

The East-West Center in Honolulu, HI issued a bulletin, in early 1997 dealing with GTL technology. ${ }^{28}$ The bulletin reported that Syntroleum did a study in 1995 of a 5,000-B/D plant on the U.S. Gulf Coast and calculated capital costs to be $\$ 27,000 / \mathrm{DBL}$. It also stated that a more recent study for a second-generation design of 5,600-B/D capacity yielded an installed cost of $\$ 17,300 / \mathrm{DBL}$. The bulletin further claimed that economies of scale associated with larger plants $(30,000-\mathrm{B} / \mathrm{D})$ could drive capital costs even lower, to the range of $\$ 12,000 / \mathrm{DBL}$ to $\$ 14,000 / \mathrm{DBL}$ on the Gulf Coast.

Capital costs for a generic GTL plant used in this evaluation are not taken from an operating GTL plant. There have been numerous reports of technological improvements and many studies indicating that GTL-plant capital costs have decreased to the mid-\$20,000/DBL range and future reductions to the midteens are anticipated. Given these circumstances, capital costs for a generic GTL plant are assigned a value of $\$ 24,000 / \mathrm{DBL}$, equal to the capital costs calculated in the Exxon/Qatar feasibility study mentioned above.

\subsubsection{Capital Costs - Alaska North Slope}

This section discusses differences in capital costs for projects constructed on the North Slope compared to projects constructed in the U.S. Gulf Coast area. Capital costs are higher on the North Slope because of a number of things. Large process plants are normally fabricated in the lower- 48 and shipped to Alaska in sections on specialized barges. More steel is required in the modules for greater stability to be able to withstand the shipping process. Depending on the weather, delays of up to 30 days have occurred because of ice on the water. After the barges arrive and are unloaded, the sections must be assembled. Because of the severe weather, all equipment must be enclosed in insulated buildings with freezertype doors. Everything must be designed for temperature extremes not seen in the Gulf Coast region. Labor costs are higher on the North Slope, as well, because living quarters have to be provided, labor rates are higher, and all food must be transported long distances.

When considering an installation on the North Slope, applying a capital cost factor of between 1.3 and 2.0 is reasonable for installations originally cost-estimated for the U.S. Gulf Coast area. A North Slope capital cost factor of 1.5 is used to calculate capital costs. Applying the 1.5 North Slope capital cost factor to the base value of $\$ 24,000 / \mathrm{DBL}$ for the generic GTL plant yields capital costs for a North Slope location of $\$ 36,000 / \mathrm{DBL}$. 
5.4.1.1 Taking Advantage of the Learning Curve. In 1989, E. W. Merrow of the Rand Corporation published a report for the U.S. DOE discussing cost improvements in chemical process technologies. ${ }^{29}$ The indented paragraphs in this section are taken directly from that report.

Cost improvement - sometimes called the learning curve or progress curve - plays a crucial role in the competitiveness of the U.S. chemical industry. More rapid cost improvement for a product, results in expanding market share and larger profits. Expectations of rapid cost improvement motivate companies to invest heavily in the development and introduction of new chemical products and processes, even if production from the first pioneer facility is economically marginal. The slope of the learning curve can also indicate whether government support of new chemical processes such as synthetic fuels can be expected to have large social benefits or to simply represent a net loss to the public treasury.

After a successful development effort has produced the first commercial plant and product, the cost of the product from that plant may not be representative of the long-run costs.

The gas-to-liquids industry is essentially still in the R\&D stages of development. The technology has been available since the 1930's; nevertheless, although there has been some production, it has been from subsidized or uneconomical plants. There has yet to be a "first commercial plant" upon which to base future cost improvements.

A number of factors, all of which tend to occur over time, act in combination to decrease the costs of successive plants and product. These include:

- Learning by plant operators and designers.

- Technical improvement.

- Economies associated with larger units.

- Decreases in raw material (feedstock) costs.

The first factor is traditionally cited as the source of the 'learning curve.' It is important to note that we are not following strictly the learning curve concept that is common in the literature. Rather, we are making a distinction between the 'learning curve' - which is presumably caused by the learning process among workers, managers, and plant designers - and 'cost improvement' - an empirically observed phenomenon that may have many sources, including those of the traditional learning curve. We do not want to limit our attention to the learning phenomenon, so this analysis is concerned with the broad subject of cost improvement, defined as the reduction in a product's unit cost that occurs as the cumulative industry production increases.

The rate of cost improvement can be described mathematically by the following equation.

$$
\begin{aligned}
C_{n} & =C_{1} n^{b}, \\
\mathrm{C}_{\mathrm{n}} & =\text { cost of the nth unit, }
\end{aligned}
$$


$\mathrm{C}_{1}=$ cost of the first unit,

$\mathrm{n} \quad=$ number of the unit being estimated, and

$\mathrm{b}=$ exponent equal to the $\log$ of the improvement-curve rate divided by the $\log$ of 2 .

The cost improvement rate for organic chemical production was found to be 73.8 percent on the average, which means that for each doubling of cumulative organic chemical production, costs decline to 73.8 percent of what they were prior to that doubling.

Gas-to-liquids processes are included in the organic chemical production industry. The exponent "b" in Eq. (1) for the organic chemicals production industry is therefore:

$b=\frac{\ln 0.738}{\ln 2.0}=-0.4383$

The 'cost of the nth unit' as given in the Rand report applies to the end-product cost. This cost is a function of capital costs, operating cost, feedstock cost, tax cost, etc. However, in this report, cost improvement is applied to capital costs instead of end-product cost. Our rationale for doing this is as follows: The two main costs that give rise to end-product cost improvements are capital costs and operating and maintenance costs. By applying the total cost improvement devised in the Rand report to the capital cost variable, we account for all the end-product cost improvement in one input variable - capital costs. While the resulting capital cost improvements might be too large using this methodology when looked at individually, they will be offset in the overall project economics by the non-improvements in other costs such as operating and maintenance costs.

In this report, we assume that there will be no other GTL production anywhere else in the world during the 30-year life of the GTL project except from this plant in Alaska, which is probably an unreasonable assumption. If the initial plant proves to be successful, other plants around the world would most likely be built, and cumulative GTL production would be accelerated, which, in turn, would accelerate the cost improvements for additional expansions in Alaska. This is not accounted for in the analyses in this report, which implies that the cost savings used in this report would be conservative and that actual cost savings could be greater than those used. However, by using this approach, we feel confident that the cost improvement defined in the Rand report is fully and adequately incorporated into this study.

The variable " $n$ " in Eq. (1) refers to cumulative production. Each time the production capacity doubles, " $n$ " is increased by one unit. Assuming the capital costs of the first GTL plant on the North Slope are $\$ 36,000 / \mathrm{DBL}$ as discussed in Section 5.4.1, the capital costs for a second plant of equal size would be reduced to $\$ 26,568 / \mathrm{DBL}$ according to Eq. (1) because the capacity is doubled. A third plant of equal size would increase the capacity by an additional 50 percent; thus, the variable " $n$ " in Eq. (1) for the third plant would be 2.5 , and the cost of the plant would be $\$ 24,093 / \mathrm{DBL}$. The addition of the fourth plant would achieve the next doubling of capacity and " $n$ " equals 3 for the fourth addition; and the cost would be $\$ 22,292 / \mathrm{DBL}$. The cost of the fifth addition of $60,000 \mathrm{bbl} / \mathrm{D}$ of capacity would be $\$ 21,475 / \mathrm{DBL}$.

\section{ECONOMIC EVALUATIONS}

\subsection{Economic Input Variables}

The LNG project evaluated here was described in detail in the 1996 DOE report and was not revised for this study except for two exceptions: values were updated from 1995 dollars to 1998 dollars and the oil price forecast was changed. The GTL project was changed to include capital cost improvements; 
data learned from the Rand report cited earlier; as well as updating costs from 1995 dollars to 1998 dollars. The Prudhoe Bay field model was revised and updated to include changes in costs, future investments, and production forecasts

\subsubsection{Oil Prices}

Several oil price forecasts are available for use. The world oil price forecast that is used as the "base" case in this study is an \$18/bbl flat price (in 1998 real dollars). The Energy Information Administration (EIA) publishes an Annual Energy Outlook (AEO) every year in which they publish a set (high, low, and reference) of oil price forecasts. The EIA projects the AEO98 reference price forecast to the year 2020. Historical world crude price as well as the projected AEO98 oil price forecast are shown in Fig. 6. This forecast increases slightly throughout the forecast period in terms of real dollars. For economic evaluations beyond the forecast period, a linear extrapolation was used.

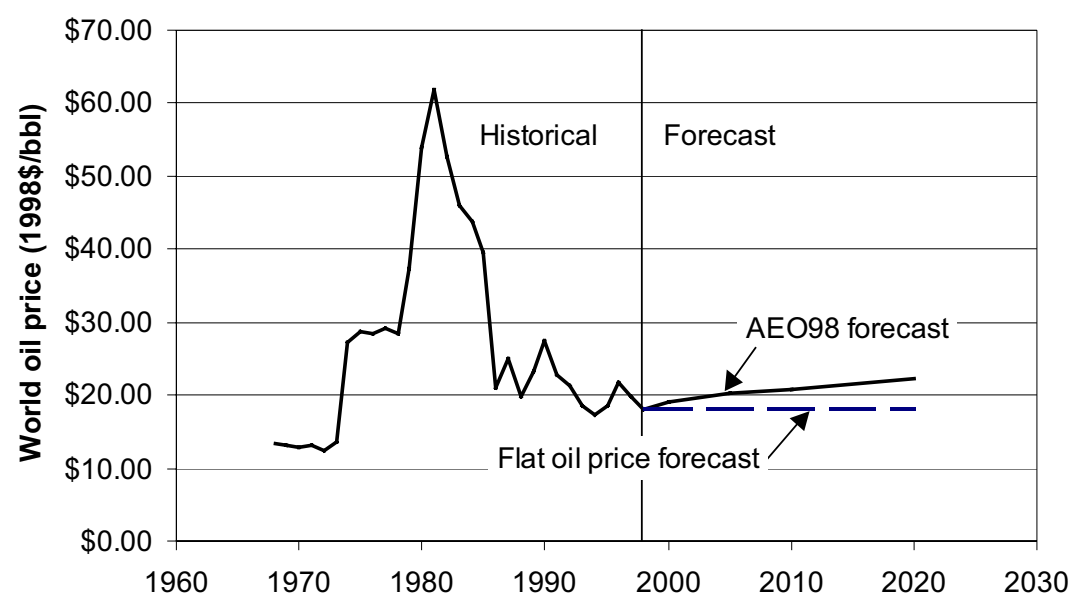

Figure 6 - Historical and forecast world oil prices. Data from Energy Information Administration.

Oil prices, since 1986 , on the average have remained relatively flat at around \$20/bbl or slightly declined. The projects being evaluated in this study are long-term projects - ending between 2036 and 2042. Oil prices will certainly vary somewhat during this period with normal vicissitudes. Although a flat oil price of $\$ 18 / \mathrm{bbl}$ may seem high or low depending on when this report is read, an $\$ 18 / \mathrm{bbl}$ oil price appears reasonable over the length of these evaluations. In addition, a flat oil price allows comparisons with other projects without the added variable of time-dependent oil prices.

\subsubsection{Inflation}

Inflation is the persistent rise in the prices of a Consumer Price Index type basket of goods, services, and commodities. In the USA and many other countries, this 'basket' is called the Consumer Price Index (CPI), which is made up of about 400 goods and services and commodities purchased by typical consumers. ${ }^{30}$ The U.S. Department of Labor, Bureau of Labor Statistics prepares the CPI on a monthly basis. The seasonally adjusted CPI for all urban consumers is plotted in Fig. 7. Historically, although the annual inflation rate has fluctuated dramatically at times, it has remained below $15 \%$ since 1940 . Since the early 1980's, it has varied between $1 \%$ and $7 \%$. In Fig. 7, the average annual inflation rate over the last ten years of $3.0 \% / \mathrm{yr}$ has been extrapolated over the approximate length of the projects evaluated. The future annual inflation rate used in the economic evaluations in this report was $3.0 \% / \mathrm{yr}$. 


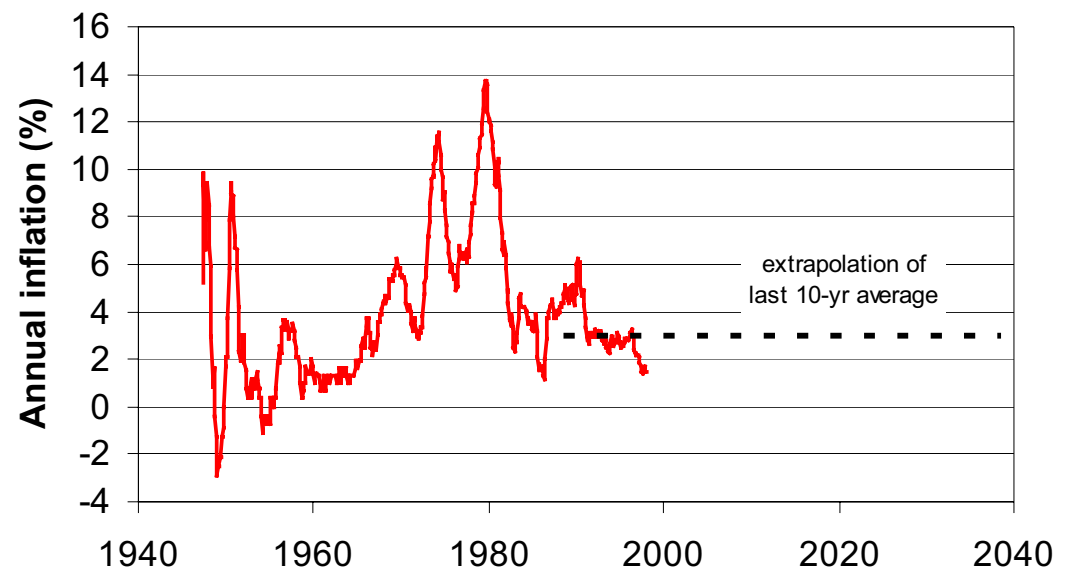

Figure 7 - Historical and projected annual inflation rate.

\subsubsection{Discount Rate}

The discount rate used in discounted cash flow analyses can be defined as the expected rate of return (ROR) that could be realized on similar alternative investments with equivalent risk. The minimum acceptable discount rate for new projects will vary for different projects and for different companies depending on the risk associated with the project, the economic climate of the nation, and the alternative investment opportunities for a given company. The major developments on the North Slope including the Prudhoe Bay field and TAPS have multiple owners with varying ownership levels and competing interests, which makes it impossible to select a discount rate representative for each company. However, an average or representative value of $10 \%$ is selected for the analyses of this study.

\subsubsection{Taxes}

The evaluations are performed on an after-tax basis. Alaska's corporate income tax, like that of most other states, is based on apportioning either domestic or worldwide income to establish the "deemed" Alaska income subject to the state nominal tax rate of 9.4\%. The apportionment fraction is the average amount of the taxpayer's property, hydrocarbon extraction, and sales in Alaska relative to that in the rest of the world. To precisely assess the state's income tax, it is necessary to anticipate what the investor's worldwide income, worldwide property, worldwide extraction, and worldwide sales with be throughout the life of the project; this is obviously impossible. To approximate the state income tax paid on project earnings, the nominal tax rate is halved to $4.7 \%$ and applied to all taxable income.

The federal income tax rate used in the analysis is $35 \%$.

\subsection{Method of Economic Evaluation}

After-tax discounted cash flow analysis was used to evaluate the gas sales options. The net present value of a project resulting from this analysis is used to compare the options. The term cash flow refers to the net inflow (revenues, savings) and outflow (operating costs, taxes, capital expenditures) of money that occurs during a given year. If costs exceed revenues, then the cash flow is negative for that year and, of course, if revenues exceed costs, then the cash flow will be positive for that year. The cash flows for each year the projects are evaluated are discounted to year zero to account for the time value of 
money. Hence, the term discounted cash flow. The rate at which future cash flows are discounted is known as the discount rate and is discussed in section 6.1.3.

The projects are quantified in terms of the net present value. The net present value (NPV) of a project is the sum of all the yearly discounted cash flows. It includes all investments, revenues, and costs of a project. The real utility of the NPV analysis is that it rolls the entire project into a dollar value that can be compared to other projects regardless of project length or timing. It enables investors to fairly and to properly compare projects and to determine which project has the greatest worth in today's dollars.

The term $\mathrm{NPV}_{10}$ is used to signify a net present value evaluated at a 10 percent discount rate. By definition, a project that produces a $\mathrm{NPV}_{10}$ equal to $\$ 0$ has a rate of return equal to 10 percent. Therefore, a project with a positive NPV 10 produces a rate of return greater than 10 percent, while a project with a negative $\mathrm{NPV}_{10}$ produces a rate of return less than 10 percent.

An economic model that incorporates the effect of gas sales, as well as oil sales, was developed to evaluate the Prudhoe Bay field. The Prudhoe Bay field is by far the largest current natural gas source on the North Slope with 21.8 Tcf of natural gas estimated to be available for a future major-gas sale (see section 2.3.7). Point Thomson may have as much as 5 Tcf available for sale according to recent estimates, with other fields offering much smaller amounts. Because Point Thomson is not a producing field and there are major concerns about its economic viability, ${ }^{1}$ an economic model for the Point Thomson unit was not constructed in this study. However, gas from the potential production of Point Thomson, or other fields, can be included in the total amount of gas sold to a gas project.

IFPS/Plus ${ }^{\mathrm{TM}}$ ver. $5.1^{\mathrm{b}}$ was the commercial software used to perform the economic evaluations. This software allows a basic economic model to be constructed and run with a number of data files representing different cases or projects. To evaluate gas sales from the North Slope, two different models were constructed: the Prudhoe Bay field model and the gas project model (the GTL plant, for example). module.

The Prudhoe Bay field model was run with three different data files along with a transportation

1) The base case data file supplies data to the Prudhoe Bay field model to evaluate the economics of the field with no major gas sales in the future. Current field practices are continued in this case with the produced gas processed and used for miscible injectant and pressure maintenance to continue the highly effective oil-recovery processes in the field, but not sold.

2) The PBU-GTL data file supplies data to the Prudhoe Bay field model to evaluate the economics of the field with major gas sales to a GTL plant.

3) The PBU-LNG data file supplies data to the Prudhoe Bay field model to evaluate the economics of the field with major gas sales to an LNG project.

4) The transportation module calculates the transportation costs associated with transporting liquids through TAPS.

The gas project model was developed to evaluate the economic viability of a gas commercialization project, either an LNG project or a GTL project. The model can be run with either the LNG data file or the GTL data file. The LNG data file supplies data to the gas project model on the LNG project and accepts gas from Prudhoe Bay, Point Thomson, or another field(s). The GTL data file provides data to

\footnotetext{
${ }^{\mathrm{b}}$ A Comshare, Inc. product.
} 
the gas project model on the GTL plant and also accepts gas from Prudhoe Bay, Point Thomson, or another field. The transportation module is used with the GTL data file to calculate transportation costs of the GTL product; however, the transportation module is not used when evaluating the LNG project because no liquids are being shipped through TAPS.

Fig. 8 illustrates the relationships between the two economic models and the data files used in conjunction with those models.

\begin{tabular}{|c|c|c|c|c|}
\hline Model & Data files & & & Model output \\
\hline Field-98 & $\begin{array}{l}\text { Prudhoe Bay with } \\
\text { no gas sales } \\
\text { Prudhoe Bay with } \\
\text { gas sales to GTL plant } \\
\text { Prudhoe Bay with } \\
\text { gas sales to LNG project }\end{array}$ & $\begin{array}{l}\text { Transportation } \\
\text { subroutine }\end{array}$ & $\begin{array}{l}- \\
- \\
\bar{E} \\
- \\
-\end{array}$ & $\begin{array}{l}\text { Net present value, } \\
\text { Gas production forecast, } \\
\text { Pipeline tariffs, } \\
\text { Cash flow forecast, } \\
\text { Revenue to state and } \\
\text { federal governments, } \\
\text { etc. }\end{array}$ \\
\hline
\end{tabular}

Figure 8 - Flow chart describing economic evaluations and relationships between data files and models.

\subsubsection{Relationship between Prudhoe Bay and Gas Project}

Both the field model and the gas project model are necessary to effectively evaluate the scenarios being considered and are tied together by the price of natural gas. The "natural gas sale price" for the field operators" model is equal to the "natural gas feed price" in the gas project model and is termed the gas transfer price. The gas transfer price is calculated with the use of the "net back" term. The "net back" refers to the 'net' fraction of the gas price sold by the gas project (GTL plant or LNG project) that is returned 'back' to the Prudhoe Bay unit operators as payment for the gas. For the LNG project, the North Slope gas transfer price in $\$ / M C F$ is calculated by the following equation.

Gas transfer price $=L N G$ price in Asia $\times$ net back.

If the East Asia LNG sale price were $\$ 3.50 / \mathrm{Mcf}$, a net back of 0.20 means that the Prudhoe Bay operators would receive $20 \%$ of $\$ 3.50$ or $\$ 0.70 / \mathrm{Mcf}$ for the gas they sell to the project.

For the GTL plant, the North Slope gas price in $\$ / \mathrm{Mcf}$ is calculated by

Gas transfer price $=$ GTL product price on North Slope $\times \frac{B T U \text { of natural gas }}{B T U \text { of GTL product }} \times$ net back. 
If the North Slope GTL product price were \$16/bbl, the natural gas BTU content were 1.150 MMBTU/Mcf, the GTL product BTU content were 5.75 MMBTU/bbl, and the net back were 0.20 , then the North Slope gas transfer price would be \$0.64/Mcf.

\subsection{Results of Economic Evaluations}

\subsubsection{Scenarios Evaluated}

6.3.1.1 Prudhoe Bay Unit Scenarios. No major gas sales. Continue with current operations utilizing the natural gas to maximize oil production. Under this scenario, oil production continues until 2025, when the economic limit of the field is reached.

Major gas sales to a gas-pipeline/LNG project beginning in 2005. Maximum gas production from Prudhoe Bay of $2.0 \mathrm{Bcf} / \mathrm{D}$ is reached in 2009 after increasing the gas production rate by $20 \%$ of the maximum per year. Ultimate oil recovery is 400 million bbl less in this scenario than in the "no major gas sales" scenario.

Major gas sales to a fast-paced GTL plant located on the North Slope beginning in 2005. This scenario follows the same gas sales rate schedule as the "sales to LNG" scenario. Ultimate oil recovery is 400 million bbl less in this scenario than in the "no major gas sales" scenario.

Major gas sales to a fast-paced GTL plant located in southern Alaska beginning in 2005. This scenario is identical to the previous scenario except an extra cost is added to natural gas sold to account for transporting it from the North Slope to southern Alaska through an 800-mile pipeline.

Major gas sales to a slow-paced GTL plant located on the North Slope beginning in 2005 . The gas production rate from Prudhoe Bay begins at $0.5 \mathrm{Bcf} / \mathrm{D}$ for 5 years and then increases to $1.0 \mathrm{Bcf} / \mathrm{D}$ for another 5 years, and so on until a maximum of $2.0 \mathrm{Bcf} / \mathrm{D}$ is reached in 2020 . Under this assumption, ultimate oil recovery will be equal to the "no major gas sales" scenario.

6.3.1.2 Natural Gas Pipeline/LNG Scenario. A potential natural gas pipeline/LNG project was evaluated to accept $2.0 \mathrm{Bcf} / \mathrm{D}$ of natural gas sales from the Prudhoe Bay unit as well as $0.5 \mathrm{Bcf} / \mathrm{D}$ from the Point Thomson unit, which lies 50 miles east of Prudhoe Bay.

6.3.1.3 Three Scenarios Evaluated for Potential GTL Plant. A fast-paced GTL scenario where a 300,000-B/D GTL plant is constructed on the North Slope to match the timing and volumes proposed by in the LNG scenario.

A slower-paced GTL construction schedule is assumed to take advantage of the learning curve associated with implementation of newer technologies. Placement is on the Alaska North Slope and this scenario is paired with the fourth scenario for the Prudhoe Bay unit - "major gas sales to slow-paced GTL plant." The GTL plant purchases natural gas from Prudhoe Bay at a maximum rate of 2.0 Bcf/D and from Point Thomson, as well, at a rate of $0.5 \mathrm{Bcf} / \mathrm{D}$.

A 300,000-B/D GTL plant (fast-paced) is located in Valdez, AK. This scenario assumes that the natural gas pipeline is built and a tariff is charged to the gas passing through the line. The assumed gas purchase rate is equal to the LNG scenario. A lower capital-cost factor (1.2) is applied at the Valdez location as opposed to a North Slope location (1.5). 
The pipeline tariff of $\$ 0.80 / \mathrm{Mcf}$ was calculated for the third GTL scenario using two independent methods. The first method used the following simple formula developed by the Alaska Department of Revenue to estimate field pipeline tariffs. ${ }^{31}$

Pipeline tariff $=\frac{\text { Cost of pipeline }(\$)}{\text { total volume to be transported }(\text { Mcf })} \times 3.35$

The cost of a natural gas pipeline has been estimated to be $\$ 6$ billion. The total volume of gas transported through the pipeline from PBU and PTU to Valdez is $25 \mathrm{Tcf}$. A pipeline tariff of $\$ 0.80$ is calculated using Eq. (5).

The other method used to calculate the gas pipeline tariff at Valdez was through amortizing the capital costs of the pipeline to get an approximate yearly cost and then dividing by the yearly rate. This method yields a natural gas pipeline tariff of $\$ 0.77 / \mathrm{Mcf}$, which is comparatively close to the tariff calculated from Eq. (5). A tariff of $\$ 0.80 / \mathrm{Mcf}$ is used in the economic evaluations of this scenario.

\subsubsection{TAPS Tariff Discussion}

The tariff that is charged for transporting liquid through the Trans-Alaska Pipeline System (TAPS) is an important economic parameter. The tariff calculation is based on costs to operate the pipeline, future investments, pipeline profit, and liquid flowrate through the pipeline. TAPS tariffs are a very important part of an analysis of projects affecting liquid production from the North Slope of Alaska. The same tariff is applied to all liquids passing through the pipeline; whether it be crude oil, natural gas liquids, or product from a GTL plant. The tariff is deducted from value of the crude oil or GTL product at downstream refineries. A higher transportation tariff reduces the value of the wellhead product.

Fig. 9 shows the differences in TAPS tariff forecasts for four scenarios described in section 6.3. All of the four scenarios share the same TAPS tariff from 1998 through 2004 because no gas is sold and no extra liquids are produced during that time.

The LNG option tracks the no-gas-sales option until 2009 when the Pt. Thomson unit begins oil and gas production. At this point until 2016, the TAPS tariff is slightly lower for the LNG option than the no-gas-sales option. After 2016, the oil production rate from PBU declines because of the unavailability of gas for EOR and offsets the additional production from PTU, which causes the tariff for the LNG option to rise above the no-gas-sales option. After 2021, the TAPS tariff for the LNG option rises dramatically when oil production from PBU is expected to cease.

In 2005, both GTL options begin to produce GTL liquids from the converted natural gas, reducing the TAPS tariff relative to the no-gas-sales option. The fast-paced GTL development produces more liquids initially than the slow-paced development and Pt. Thomson is developed sooner, which combine to reduce the tariff more rapidly because of the higher volume of liquid flowing through the pipeline. However, after 2022, the slow-paced development enjoys a lower TAPS tariff because of changes in oil production from PBU. In the fast-paced development, PBU stops producing crude oil in 2021, while the unit continues to produce oil until 2025 in the slow-paced scenario. Also, Pt. Thomson begins production of the GTL product and natural liquids beginning in 2025, which helps keep the tariff lower for the slowpaced GTL development.

Besides improving the economics of the Prudhoe Bay and the Point Thomson units, lower TAPS tariffs positively impact the economics of all other oil producing fields that transport liquids through the trans-Alaska pipeline system. The benefit of lowering TAPS tariffs because of the addition of GTL products to these other fields is not quantified in this report, but is expected to be significant as a whole. 


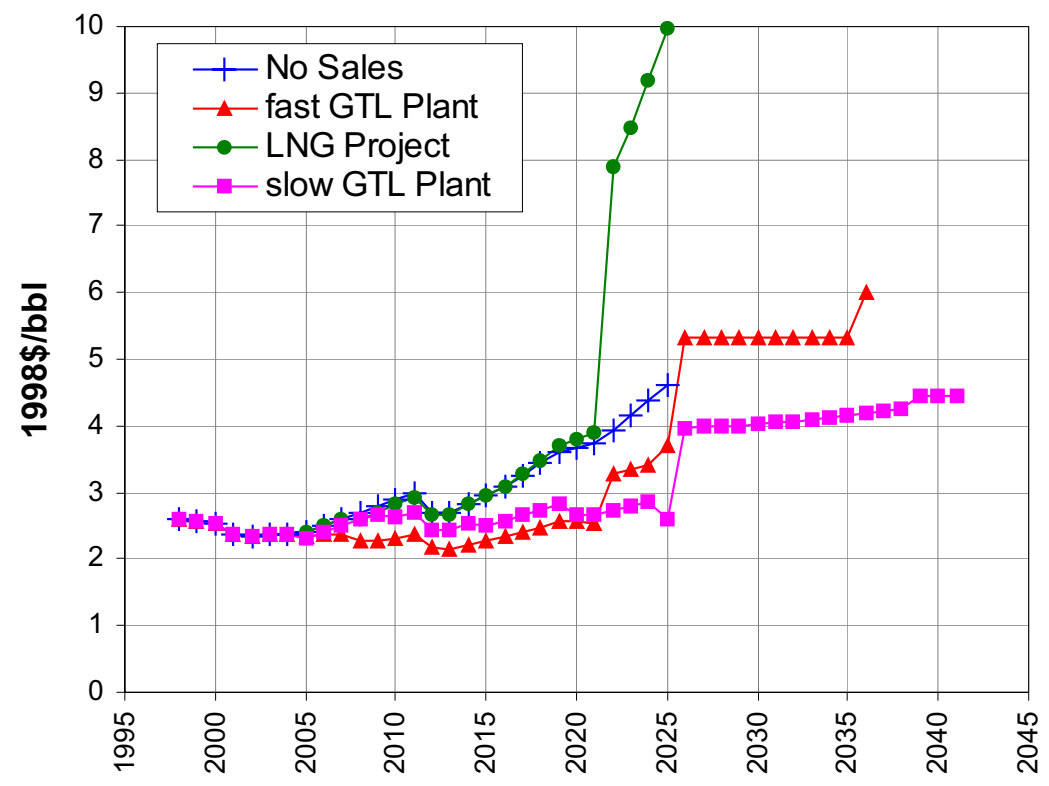

Figure 9 - TAPS tariff forecasts in $1998 \$$ for four scenarios.

\subsubsection{Results}

Results of the economic evaluations are best represented by the net present value of the project. The term $\mathrm{NPV}_{10}$ represents the net present value evaluated at a discount rate of $10 \%$. Table 1 shows the results of the evaluations described above. Project economics (meaning the sum of the field and gas marketing scheme) of all the scenarios are linked together by way of the natural gas price or gas transfer price. The gas transfer price for each scenario was optimized between the gas seller (PBU) and the gas buyer (gas marketing scheme) by varying the net back fraction until the combined $\mathrm{NPV}_{10}$ was maximized.

Table 1. Economic evaluations of major gas sales from the North Slope of Alaska.

\begin{tabular}{|l|l|r|}
\hline Scenario & Entity & $\mathrm{NPV}_{10}$ (\$, millions) \\
\hline \multirow{2}{*}{$\begin{array}{l}\text { Major gas sales to gas- } \\
\text { pipeline/LNG-plant }\end{array}$} & Incremental Prudhoe Bay unit & 589 \\
& Gas-pipeline/LNG-plant & $-2,991$ \\
\cline { 2 - 3 } & Total & $-2,402$ \\
\hline $\begin{array}{l}\text { Major gas sales to GTL } \\
\text { plant on North Slope (fast- } \\
\text { paced) }\end{array}$ & Incremental Prudhoe Bay unit & 914 \\
\hline \multirow{2}{*}{$\begin{array}{l}\text { Major gas sales to a GTL } \\
\text { plant in southern Alaska } \\
\text { (fast-paced) }\end{array}$} & Total & $-1,297$ \\
\hline $\begin{array}{l}\text { Major gas sales to GTL } \\
\text { plant on North Slope (slow- } \\
\text { paced) }\end{array}$ & Gncremental Prudhoe Bay unit & -383 \\
\cline { 2 - 3 } & Total & 542 \\
\cline { 2 - 3 } & GTL plant & $-1,908$ \\
\cline { 2 - 3 } & Total & $-1,366$ \\
\hline
\end{tabular}


In the evaluation of scenarios involving the Prudhoe Bay unit, low net back fractions can cause cash flows to become negative after oil operations cease. In cases such as these, only net back fractions that were high enough to keep Prudhoe Bay yearly cash flows positive were evaluated. Table 1 shows the results of the economic evaluations. The net present value of the incremental Prudhoe Bay unit given in Table 1 is simply the difference between the NPV $\mathrm{N}_{10}$ of the Prudhoe Bay unit without any gas sales and the $\mathrm{NPV}_{10}$ of the Prudhoe Bay unit with major gas sales. A negative incremental $\mathrm{NPV}_{10}$ indicates that the Prudhoe Bay unit is worth more if the gas is not sold.

\subsubsection{Discussion of Results}

Evaluation of the Prudhoe Bay unit economics for the gas sales scenarios required the comparison of the economics of the each gas sales scenario with the economics of the base scenario (no major gas sales). If the $\mathrm{NPV}_{10}$ of PBU with a gas sales option is positive, but still less than the base scenario, then, obviously, it would make economic sense from the PBU operator's point of view to not market the gas. The 'incremental Prudhoe Bay unit' in Table 1, represents the difference between the NPV 10 of the Prudhoe Bay unit with major gas sales and the $\mathrm{NPV}_{10}$ of the Prudhoe Bay unit with no major gas sales.

The economic results shown in Table 1 were achieved by varying the net back until the combined $\mathrm{NPV}_{10}$ 's of the Prudhoe Bay unit and the gas marketing scheme (total scenario economics) reached a maximum. This approach assumes that the total scenario economics are maximized with the only constraint being that the Prudhoe Bay unit have a positive cash flow while production operations were ongoing.

The net back is a variable that sets the transfer price for the natural gas between the producer and the buyer (LNG project or GTL project), and is explained in section 6.2.1. The gas transfer price is a key variable in the economic evaluation of both the Prudhoe Bay field and the gas-marketing scheme. In this analysis, the transfer price is consistent within each scenario; that is, the gas producer sells the gas at the same price that the LNG or GTL project buys it.

Because the transfer price is a negotiated percentage of the product sale price it will be different for each scenario. A higher net back or transfer price increases the gas sales price on the North Slope and means higher profits for the Prudhoe Bay unit and lower profits for the gas-marketing project. A lower net back means lower profits for the Prudhoe Bay unit and higher profits for the gas-marketing project because North Slope gas price is lower. Figures 10, 11, 12, and 13 show how the project economics varied with respect to the net back.

Of the four gas sales scenarios (see Table 1), the slow-paced North Slope GTL development scenario is the only one with a positive incremental combined net present value using a discount rate of $10 \%$. A negative $\mathrm{NPV}_{10}$ does not necessarily mean that a project loses money; it simply means that the rate of return for that scenario is less than $10 \%$ (the discount rate). A lower discount rate may show positive net present values for some or all the scenarios; however, this dependence was not quantified.

The gas sales revenues of slow-paced North Slope GTL plant are realized later in the life of this scenario than in the fast-paced GTL scenarios and the LNG scenario, which tends to decrease the net present value of the project. However, the savings in capital costs associated with the "learning curve" that are incorporated into this option outweigh the added discount in revenue caused by delaying the gas sales.

The total scenario for the GTL plant at a southern Alaska location includes the Prudhoe Bay unit, a gas-pipeline/LNG project, and a GTL plant in southern Alaska. This placement for the GTL plant allows some potential advantages compared to a North Slope location. (In this case, the capital cost investment follows the same schedule as the fast-paced GTL plant development.) The capital cost factor 


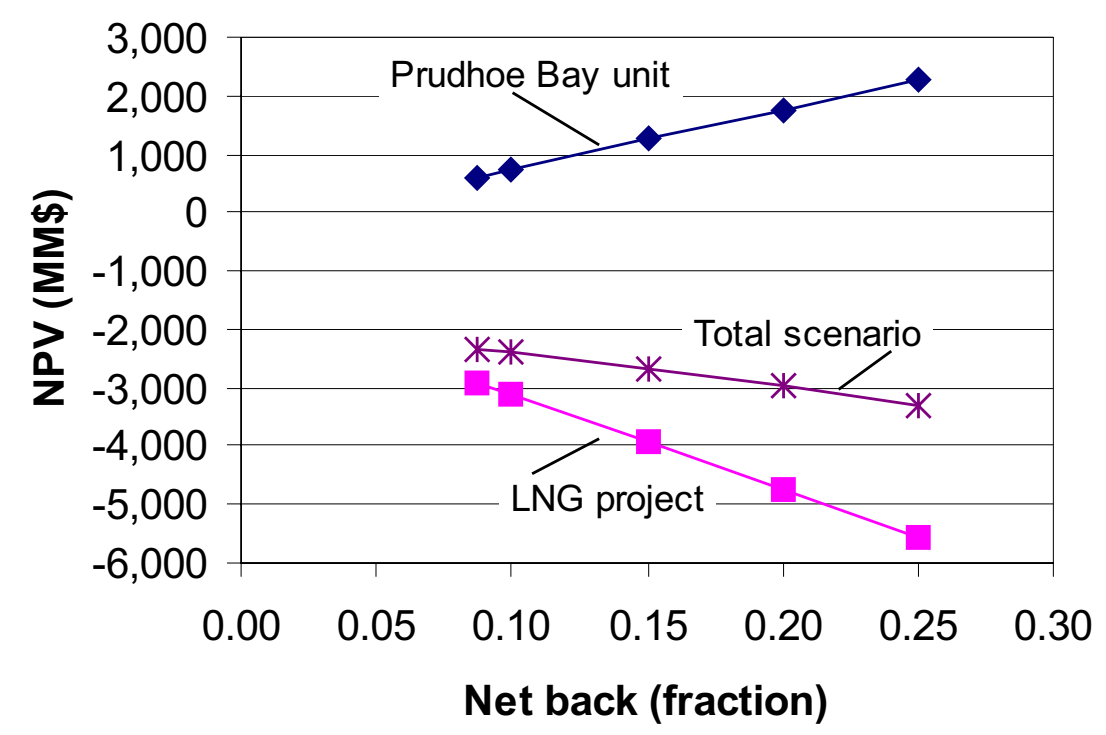

Figure 10 - NPV calculations for gas sales to LNG scenario.

would be less for a southern location than for the North Slope because of reduced shipping, labor, and materials costs. In the economic evaluation, the capital cost factor was lowered from 1.5 (for the North Slope location) to 1.2. The other major change in evaluations is the additional price of the natural gas at Valdez. The $\$ 6$ billion gas pipeline transporting natural gas from the North Slope to Valdez would still be constructed; adding about $\$ 0.80$ /Mcf to the gas feed cost (see section 6.3.1.3 for more detail). However, the additional cost of the natural gas feed more than offsets the reduced capital costs associated with the Valdez location.

The LNG scenario evaluated here is the same as in the 1996 DOE report except that the costs were updated from 1996 dollars to 1998 dollars and the \$18/bbl flat oil price forecast was used instead of the forecast used in the 1996 study. We did not include possible cost savings in pipeline construction nor

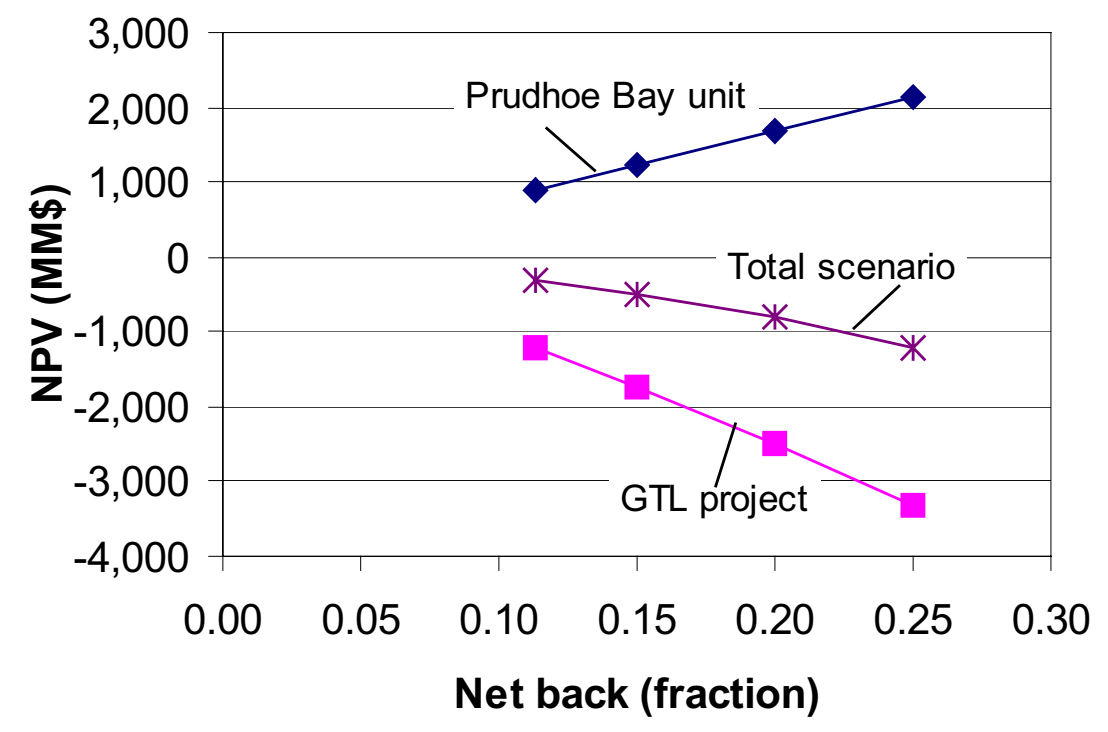

Figure 11 - NPV calculations for gas sales to a North Slope GTL plant (fast-paced) scenario. 


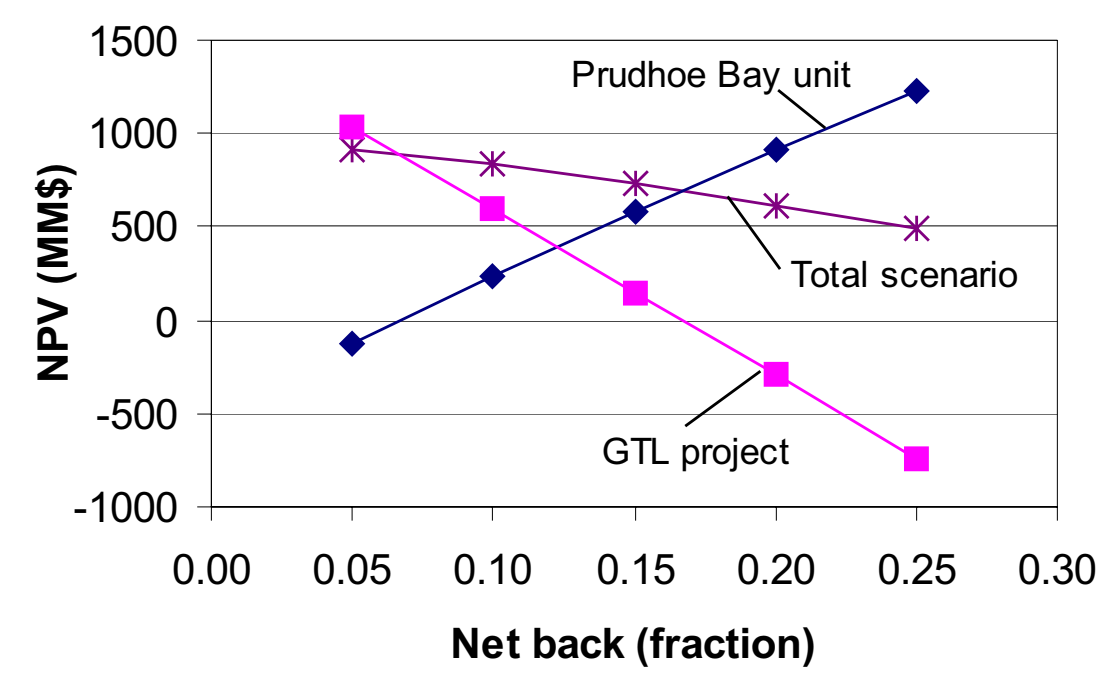

Figure 12 - NPV calculations for gas sales to a North Slope GTL plant (slow-paced) scenario.

did we include the possible effects of the Stranded Gas Act, which could reduce tax payments in the earlier portion of the project.

We left the LNG scenario unchanged from the 1996 DOE report with the exception of the oil price forecast and updating costs from 1996 dollars to 1998 dollars because it provided a base point to compare advances in GTL technology. In the 1996 DOE study, the evaluation of the LNG option and the fast-paced GTL option resulted in relatively equivalent economic scenarios. However, the fast-paced GTL development scenario that includes technological and cost improvements now has a decided advantage over the LNG scenario. When the added cost improvements associated with the learning curve are included, the slow-paced GTL development scenario is even more attractive. We should note, however, that potential cost savings in the LNG scenario (see section 3) were not included in the economic evaluation of this scenario. In addition, potential tax savings associated with the Alaska Stranded Gas Devel-

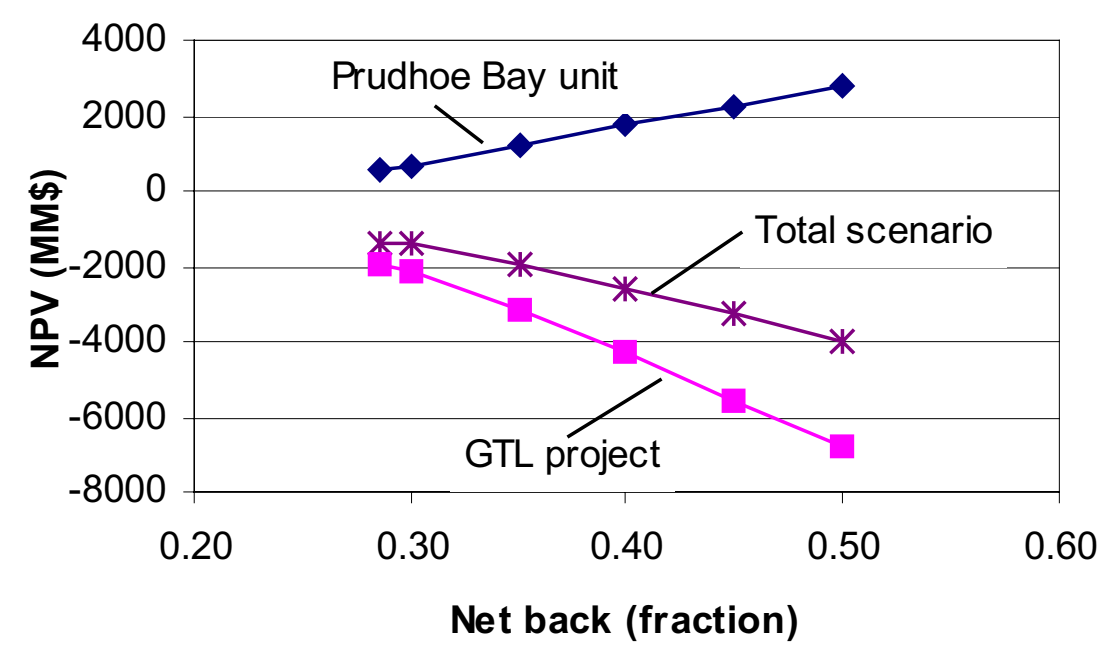

Figure 13 - NPV calculations for gas sales to a GTL plant (fastpaced) in southern Alaska. 
opment Act (see section 4) were not included in the economic evaluation.

\subsubsection{Sensitivity Analyses}

There are many sensitivity analyses that could be run on these evaluations. Learning the ramifications of varying input parameters is important to understanding project economics. As this study was primarily concerned with economics of gas-to-liquids technology Alaska, sensitivities were performed only on the GTL plant portion of the total scenarios. The field portion of the scenarios was not further included in the sensitivity analyses. The object of the analysis was to determine which input parameters cause the greatest effect on project economics. This information is vital in determining those parameters that offer the greatest potential for increasing or decreasing economic viability. These parameters require the most attention and are natural targets for further study by increasing research efforts.

The parameters selected for the sensitivity analysis were:

- Capital costs for a GTL plant on the Gulf Coast

- World oil price

- North Slope cost factor applied to capital costs

- Premium of the GTL product over crude oil prices

- Operation and maintenance costs of GTL plant

- Rate of cost improvement on subsequent GTL plant capacity

- Federal income tax rate

- Total GTL plant efficiency

- Natural gas feed BTU content per cubic foot

- Alaska state income tax rate

- GTL product BTU content per barrel

Fig. 14 shows the result of a sensitivity analysis of the input data for the slow-paced GTL plant development. The input parameter that influences the economical output is that with the longest bar and is placed at the top of the plot; while the parameter with the least influence is placed at the bottom. The numbers on each end of the respective horizontal bars indicate the possible range of the variable in ques-

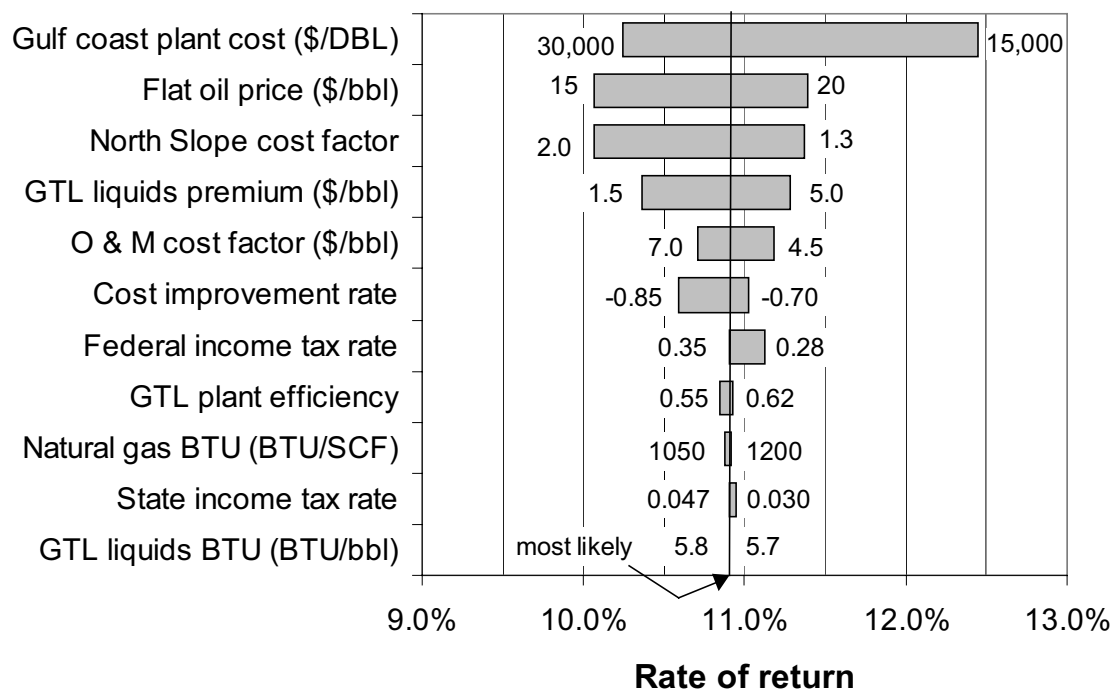

Figure 14 - Sensitivity of input parameters with respect to project economics for the slow paced, staged GTL development scenario. 
tion. The vertical "most likely" line on the figure indicates the default value for each variable.

Each input parameter was varied separately and independently from the other parameters and, therefore, the horizontal bar represents the range in ROR caused by varying only that particular variable. For example, as the world crude-oil price rises from a flat $\$ 15 / \mathrm{bbl}$ to $\$ 20 / \mathrm{bbl}$, the ROR of the Alaskan GTL project increases from 10.1 percent to 11.4 percent. The four most critical variables are the Gulf Coast GTL plant cost, the world oil price, the North Slope cost factor, and the GTL liquids per barrel premium. The ROR using the most likely values for each of the variables is 10.9 percent as shown in Fig. 14.

\subsubsection{Monte Carlo Analysis}

The Monte Carlo simulation technique permits a "probabilistic analysis" of project economics by applying probability distributions to the input parameters. Probabilistic sensitivity analyses do not compute a single result, but instead, the outcome is a range over which the results vary. In some investment situations, the shape of the computed curve is more important than the most expected value. For example, a project with an expected ROR of 20 percent with a very wide distribution might be considered less desirable than a project with an expected ROR of 15 percent and a very narrow distribution.

A basic tool of probability theory is the use of a range of values to describe input variables that cannot adequately be quantified by single value estimates. For example, the determination of the least, greatest, and most likely values of a variable will more accurately quantify a variable than will the average value.

Of the many possible distributions to describe input variables, the triangular distribution is perhaps the easiest distribution to employ. It requires an estimate of the minimum expected value, the maximum expected value, and the most likely value. Fig. 15 illustrates the form of this distribution.

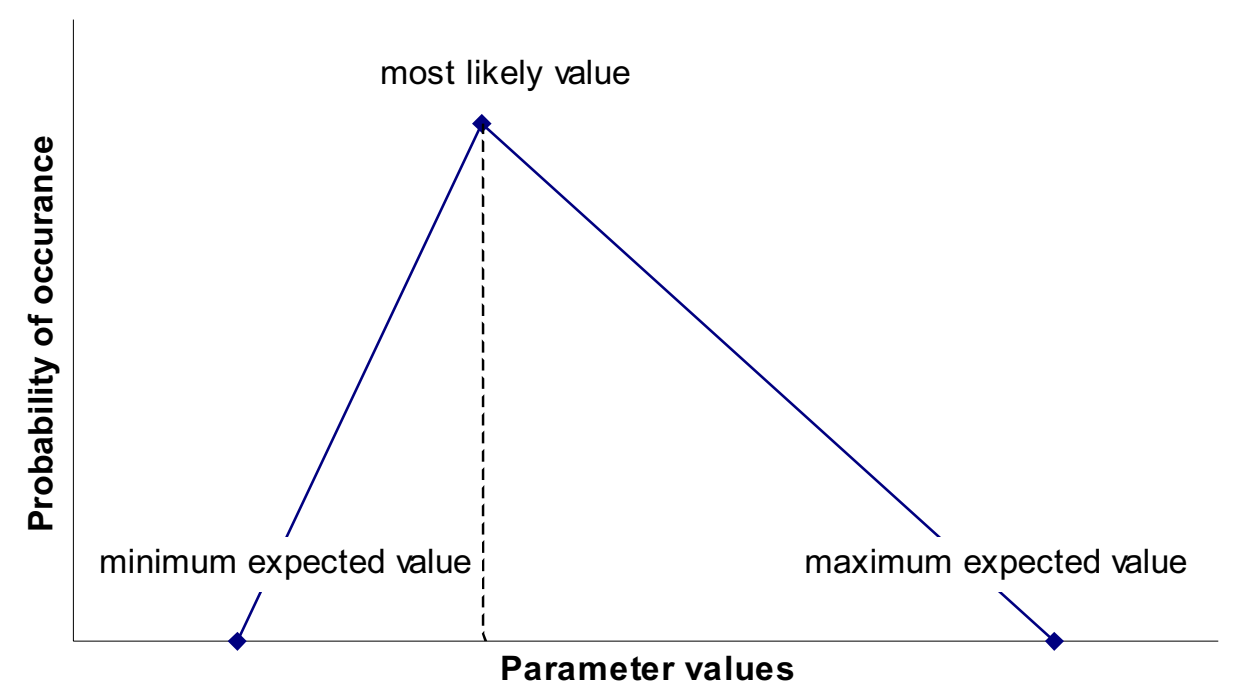

Figure 15 - Example of a triangular distribution of an input variable for Monte Carlo analysis.

In this Monte Carlo analysis, the probability distributions for all the input parameters are modeled using triangular distributions. The possible range of values for GTL plant located on the U.S. Gulf Coast 
was discussed in section 5.4. The world oil price forecasts and variations are discussed in section 6.1.1. The capital cost factor applied to projects for placement on the North Slope of Alaska is discussed in section 5.4.1. The premium over the price of crude oil applied to the GTL product is discussed in section 5.3. Operation and maintenance $(\mathrm{O} \& \mathrm{M})$ costs for large plants such as a GTL plant can be effectively approximated on a cost-per-output-barrel basis. The most likely value for $\mathrm{O} \& \mathrm{M}$ costs used in this analysis is $\$ 6 / \mathrm{bbl}$, with a minimum of $\$ 4 / \mathrm{bbl}$ and a maximum of $\$ 7 / \mathrm{bbl}$. The rate of cost improvement for successive GTL plants is discussed in section 5.4.1.1. The maximum expected values for federal and state income taxes are equal to the most likely values of 0.35 and 0.047 respectively. The minimum expected values were taken to be $80 \%$ of the most likely values; or, 0.28 for federal and 0.03 for the state. The efficiency of a GTL plant is estimated to be $60 \%$ (most likely) with a minimum of $55 \%$ and a maximum of $62 \%$. The BTU content of the natural gas feed and the GTL product were previously discussed by Thomas et al. ${ }^{1}$ Table 2 tabulates the minimum, maximum, and most likely values for the input parameters varied as part of the Monte Carlo analysis.

Table 2. Minimum, maximum, and most likely values for triangular distributions used in Monte Carlo analysis.

\begin{tabular}{lccc}
\hline & $\begin{array}{c}\text { Minimum expected } \\
\text { value }\end{array}$ & Most likely value & $\begin{array}{c}\text { Maximum expected } \\
\text { value }\end{array}$ \\
\hline Gulf coast plant cost $(\$ / \mathrm{DBL})$ & 15,000 & 24,000 & 30,000 \\
Flat oil price $(\$ / \mathrm{bbl})$ & 15 & 18 & 20 \\
North Slope cost factor & 1.3 & 1.5 & 2.0 \\
GTL liquids premium $(\$ / \mathrm{bbl})$ & 1.5 & 3.5 & 5.0 \\
O \& M cost factor $(\$ / \mathrm{bbl})$ & 4.5 & 6.0 & 7.0 \\
Cost improvement rate & -0.70 & -0.74 & -0.85 \\
Federal income tax rate & 0.28 & 0.35 & 0.35 \\
GTL plant efficiency & 0.55 & 0.60 & 0.62 \\
Natural gas BTU $(\mathrm{BTU} / \mathrm{SCF})$ & 1050 & 1150 & 1200 \\
State income tax rate & 0.030 & 0.047 & 0.047 \\
GTL liquids BTU $(\mathrm{BTU} / \mathrm{bbl})$ & 5.70 & 5.75 & 5.80 \\
\hline
\end{tabular}

In a Monte Carlo analysis, a value is calculated for each distributed input variable from random numbers. Then, using the randomly selected parameter values, the ROR is calculated. This process is repeated, picking a new set of random numbers to determine the ROR of the project. For this analysis, the ROR was calculated repeatedly (10,000 iterations) to get a smooth rate-of-return distribution.

6.3.6.1 Results of Monte Carlo Analysis. Fig. 16 is a plot of the probability-of-occurrence versus rate-of-return for a slow-paced GTL plant development on the North Slope. Fig. 17 was obtained by plotting the cumulative probability of the ROR outcome. From Fig. 16, possible rates of return can range from 8.7 percent to 13.1 percent. However, from Fig. 17, a 90 percent confidence interval on the rate of return of between 9.8 percent and 11.9 percent can be obtained by picking the 5 percent and 95 percent cumulative probability with their corresponding rates of return. The median value of 10.8 percent indicates that half of the time, a rate of return calculation would return a value of 10.8 percent or greater.

The median ROR of 10.8 percent is slightly lower than the 10.9 percent ROR calculated when using the most likely values for the input parameters. This difference occurs because the triangular distributions of most of the input parameters are skewed. For example, the flat-oil-price input variable ranges from 15 to 20, with 18 being the most likely. However, the average value of the distribution is actually 17.67 , which is slightly less than the most likely value of 18 . The standard deviation is 0.7 percent, which demonstrates that the results are tightly centered on the average of 10.8 percent. 


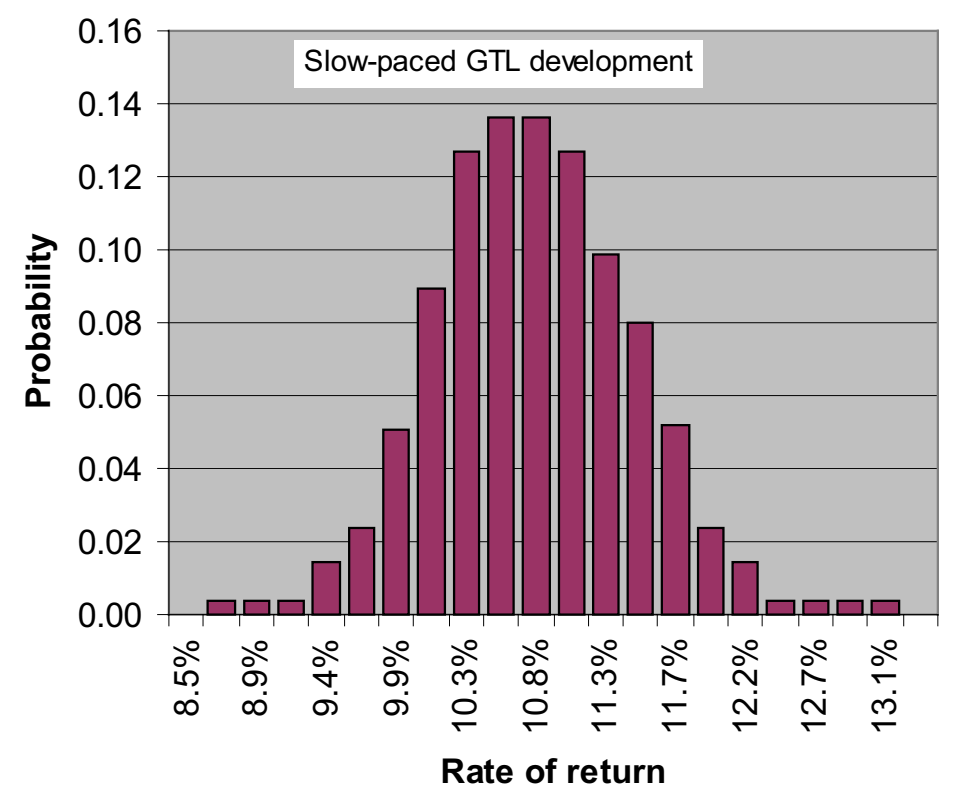

Figure 16 - Frequency plot of the rate of return for a slow-paced GTL plant development after 10000 iterations.

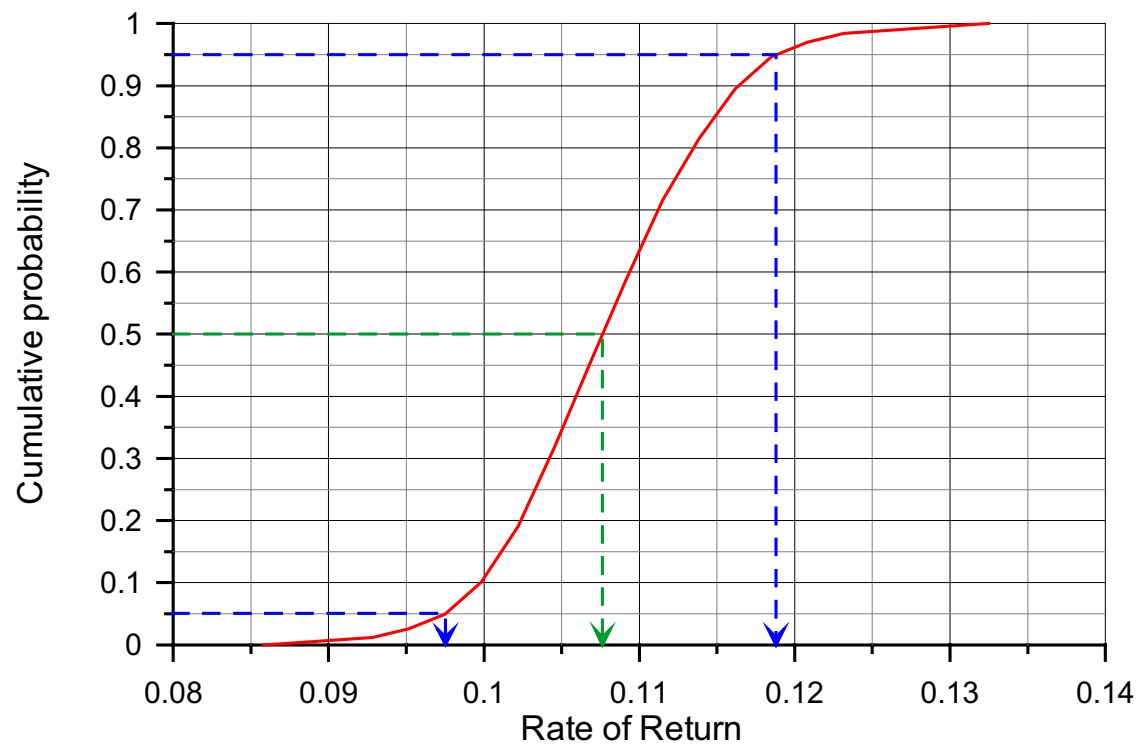

Figure 17 - Cumulative probability of occurrence for the rate of return of a slowpaced GTL plant development. 


\section{SUMMARY}

The Alaska North Slope has a vast natural gas resource that is currently being used to enhance oil recovery. It is estimated that the Prudhoe Bay field alone will have $21.8 \mathrm{Tcf}$ of natural gas available for sale after oil operations cease. Currently, there are two broad schemes proposed for commercializing the natural gas on the North Slope. One is the proposed gas-pipeline/LNG-plant scenario; the other converts the natural gas to syn-crude in a North Slope GTL plant, eliminating the need for an additional pipeline from the North Slope.

The purposes of this report were to investigate and explore the effect of applying new technology to the economics of a proposed GTL plant, to evaluate the potential of a slower-paced deployment of GTL technology, and to evaluate the effect of GTL plant placement on economics.

Of the gas marketing scenarios evaluated, results indicate that the slow-paced GTL scenario is the only one with a rate of return greater than 10 percent. The other scenarios did not show positive net present values under the economic conditions selected for the simulations. Their rank, in order of net present value, is as follows: slow-paced GTL development, no-major-gas-sales, fast-paced GTL development, fast-paced GTL development in southern Alaska, and finally a gas-pipeline/LNG project.

The slow-paced GTL development would allow cost savings on subsequent expansions. These assumed savings along with the lowering of the transportation tariff combine to distinguish this option for marketing the North Slope gas from the other scenarios. Critical variables that need further consideration include the GTL plant cost, the GTL product premium, and operating and maintenance costs. Reducing these costs or increasing the premium could dramatically increase the profitability of the GTL process. Understanding these variables better and reducing their uncertainty would allow a more accurate prediction of economic profitability. Further study of these variables (GTL plant cost, GTL product premium, and $\mathrm{O} \& \mathrm{M}$ costs) is recommended. In addition, a study to quantify the benefit of a tariff reduction caused by a North Slope GTL plant to the economics of other fields (besides Prudhoe Bay) is also recommended. 


\section{APPENDIX}

Comparison of Six Gas-to-Liquids Technologies ${ }^{c}$

${ }^{\mathrm{c}}$ Based on information provided by the Alaska Department of Revenue. 


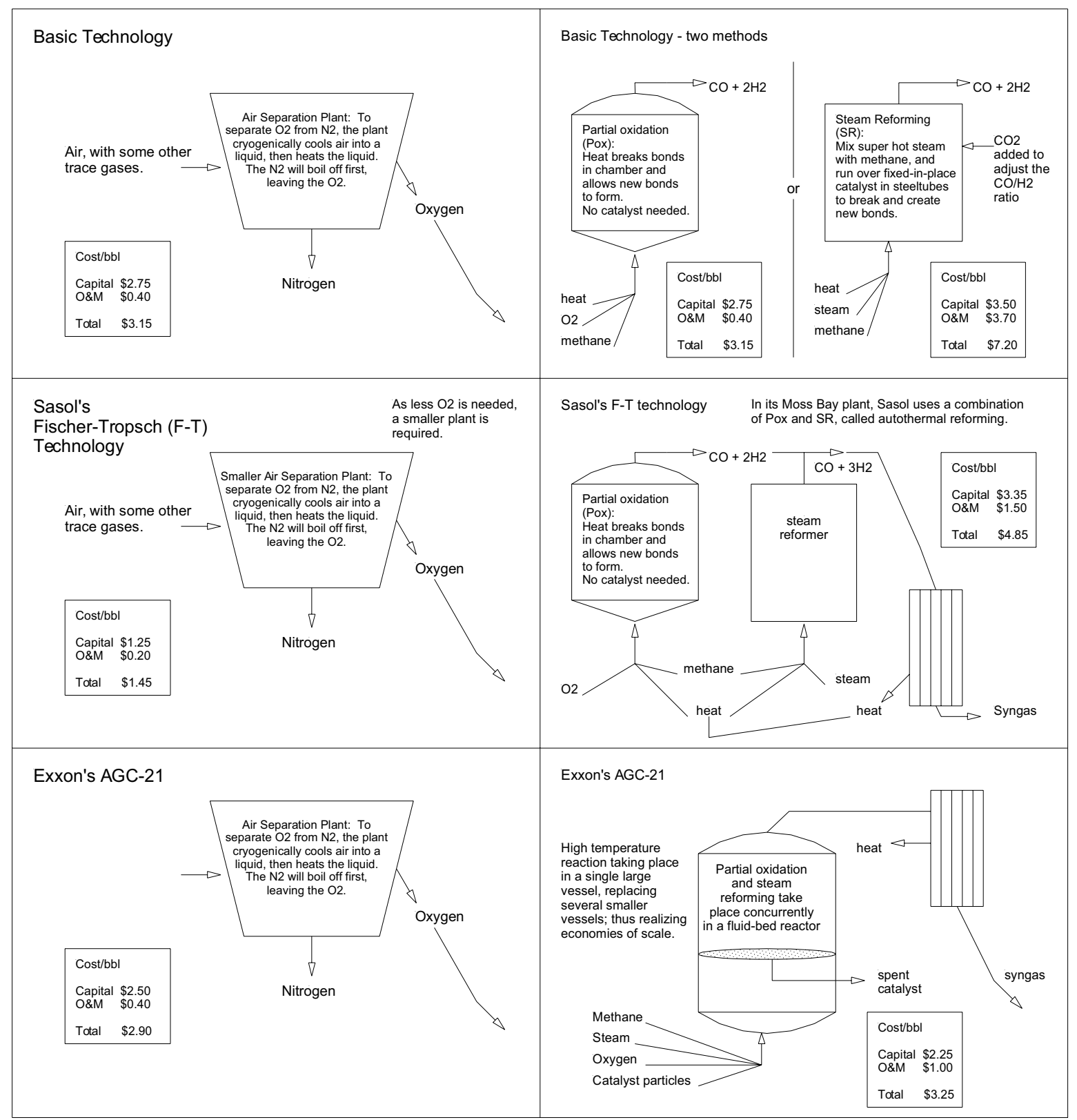




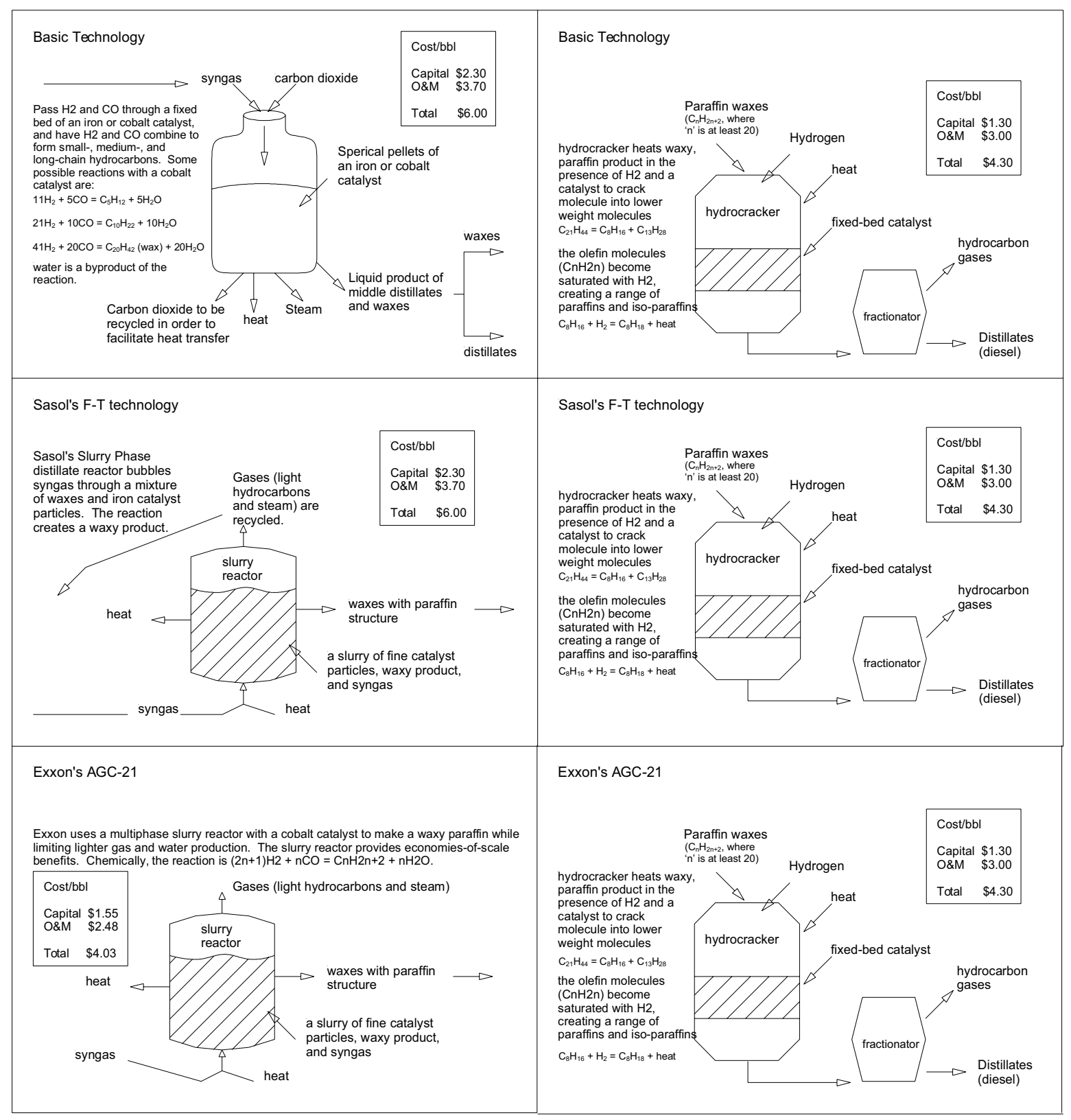




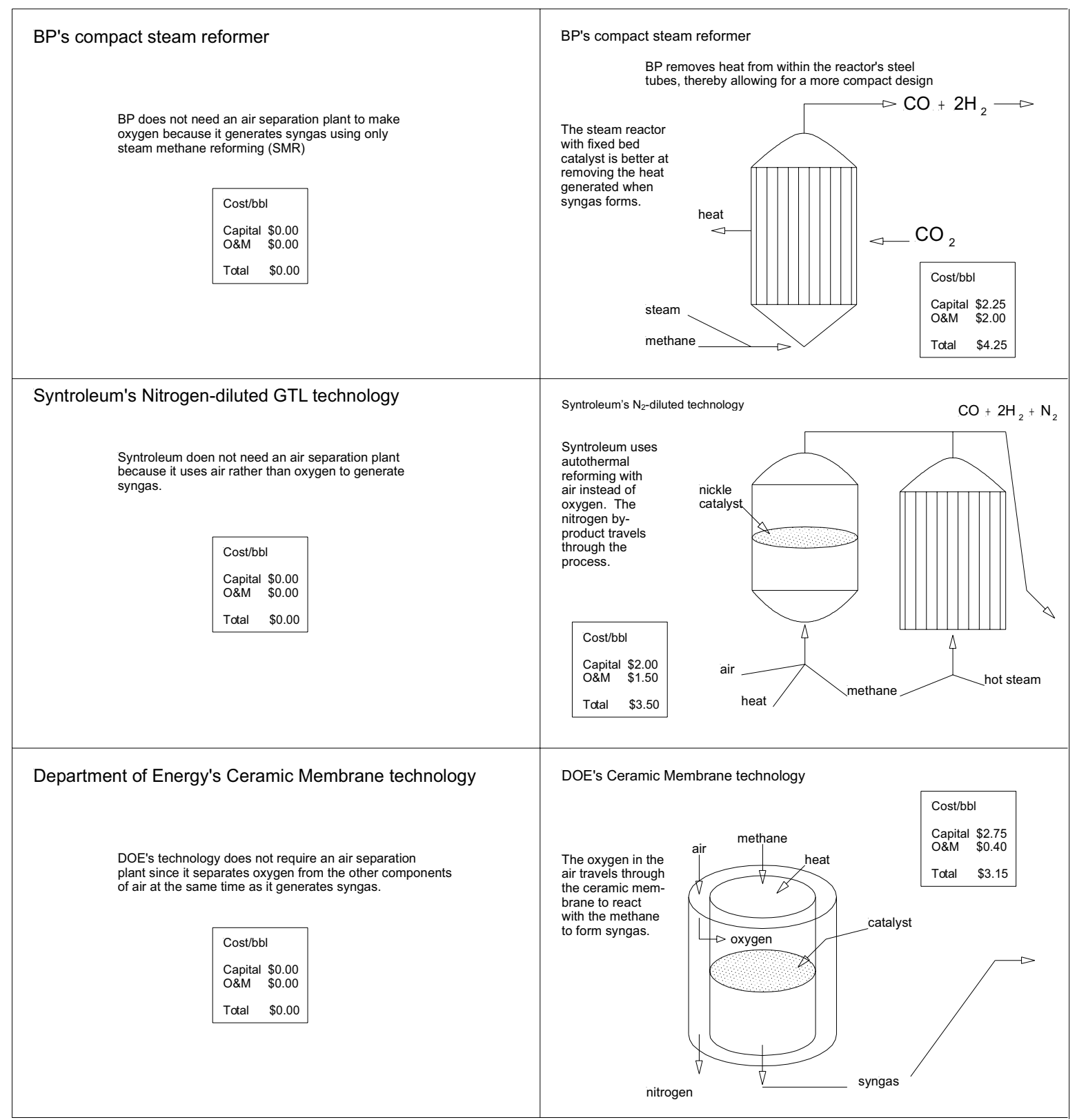




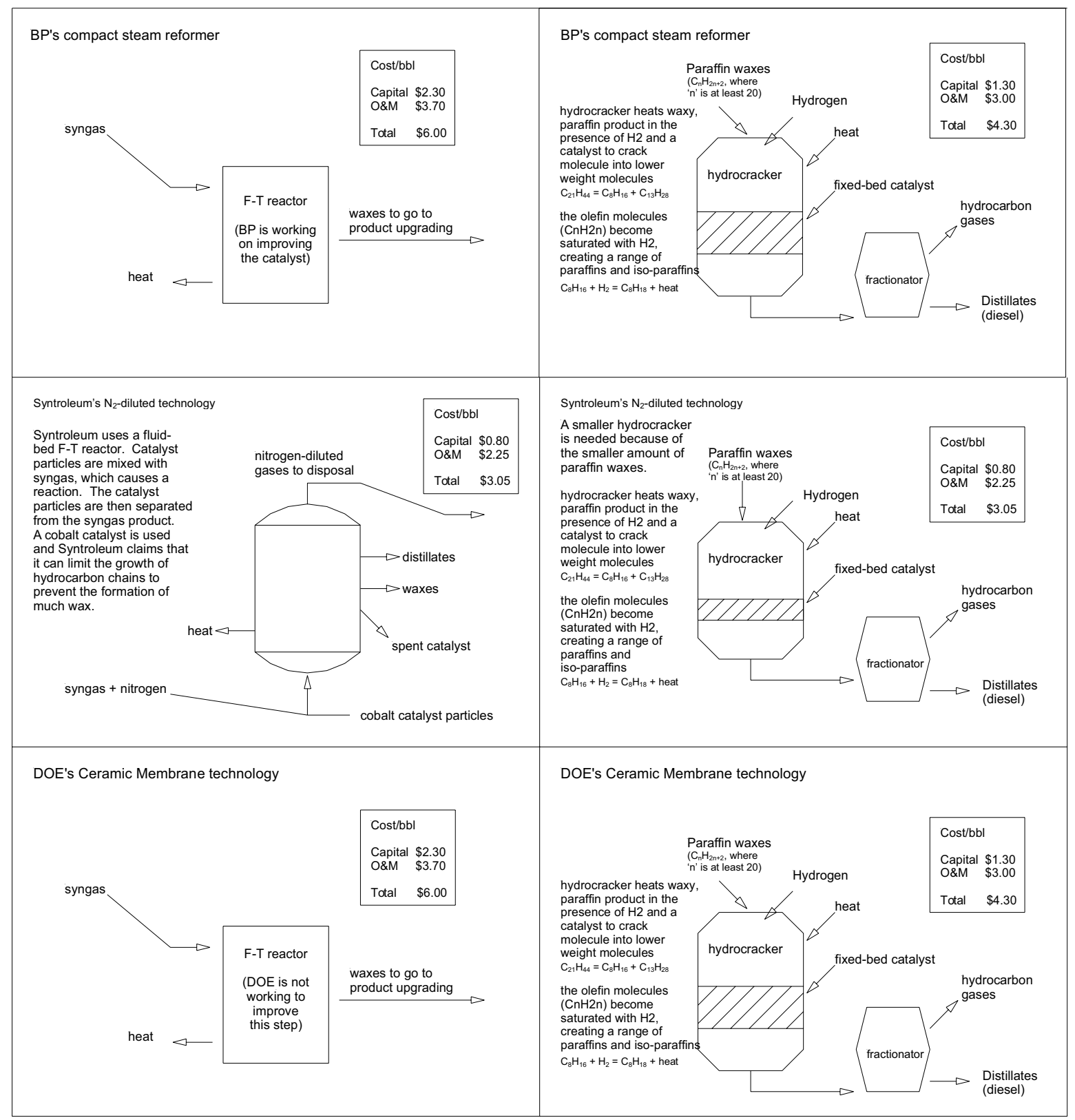




\section{REFERENCES}

1 Thomas, C.P., Doughty, T.C., Hackworth, J.H., North, W.B., and Robertson, E.P.: "Economics of Alaska North Slope Gas Utilization Options," INEL-96/0322 (August 1996).

2 “More Oil in ANWR," Petroleum News Alaska, Vol. 3, No. 5, (May 25 - June 21, 1998) p B1.

"Discovery at Sourdough," Petroleum News Alaska, Vol. 2, No. 3, (March 1997) p A1.

"Group wants fast oil lease sales in Alaska reserve," Reuters newswire, (September 9, 1998).

"ARCO to participate in 1,100 development penetrations in next five years," Petroleum News Alaska, Vol. 3, No. 2 (Feb 23-Mar 22, 1998) p A18.

6 ARCO 1997 Security Analyst Meeting - Upstream Operations, Ken Thompson, Figure 54.

7 "Historical and Projected Oil and Gas Consumption," (April 1998) ADNR - DOG, Table 1, Table 2A and Table 3.

8 “Prudhoe Reserves Get 1-Bil Boost,” Platt's Oilgram News, Vol. 71, No. 137 (July 16,1993) p 2.

9 ARCO 1997 Security Analyst Meeting - Upstream Operations, Ken Thompson.

10 “Alaska North Slope Gas Commercialization Team - Report to the Governor," Wilson L. Condon, Commissioner - Department of Revenue, John T. Shively, Commissioner - Department of Natural Resources, and Bruce M. Botelho, Attorney General (7 January 1998).

11 "Role of technology development at ARCO," Petroleum News Alaska, Vol. 3, No. 2 (Feb. 23 - Mar. 22, 1998) p B1.

12 "Exxon forms GTL study group," Petroleum News Alaska, Vol. 3, No. 6 (June 22 - July 26, 1998 ) p A3.

13 “Improving the Odds," Petroleum News Alaska, Vol. 3, No. 7 (July 27 - Aug. 30, 1998) p A1.

14 Press releases from CSX Corp. and Foothills Pipe Lines Ltd. (11 August 1998).

15 LNG Market Assessment by Zeus Development Corp. (1998).

16 Meet Alaska '97, the $14^{\text {th }}$ Annual Conference for Alaska's Business Community.

17 “Reserves Boosted for Indonesia’s Tangguh Project,” PI/Dwights International Industry News (August 24-31, 1998).

18 “Governor's North Slope gas development bill passes Legislature,” Petroleum News Alaska, Vol. 3, No. 5 (May 25 - June 21, 1998) p A8.

19 Pedro van Meurs: "Suggestions for New Terms for the Alaska North Slope LNG Project - Background Report," (12 February 1997) van Meurs \& Associates Ltd., Calgary, Alberta, Canada.

20 "New Tax Attitude," Journal of Alaska Business and Commerce (March 2, 1998) p 11.

21 J. Eilers et al.: "The Shell Middle Distillate Synthesis Process (SMDS)," Catalysis Letters, 7 (1990) 253-270.

22 "SLH Corporation Announces Syntroleum Agreement with Enron Capital and Trade Resources," Business Wire (Feb. 24, 1998).

23 B. Eisenberg, L.L. Ansell, R.A. Fiato, and R.F. Bauman: “Advanced Gas Conversion Technology for Remote Natural Gas Utilization," presented at the $73^{\text {rd }}$ Annual GPA Convention (March 7-9, 1994) New Orleans, LA.

24 B.M. Everett, B. Eisenberg, and R.F. Bauman: "Advanced Gas Conversion Technology: A New Option for Natural Gas Development," presented at the First Doha Conference on Natural Gas (March 14, 1995) Doha, Qatar.

25 "Gas-to-Liquids Technology - Dawning of New Era for Global Natural Gas," Salomon Brothers Inc. (November 8, 1996).

26 Survey of 1998 data from Oil \& Gas Journal, Statistics section on gross refining margins.

27 "Gas-to-Liquids Technology - Dawning of New Era for Global Natural Gas," Salomon Brothers Inc. (November 8, 1996).

28 W.S. Pintz: "Economical Conversion of Natural Gas to Liquid Synthetic Fuels: The Next Megatrend?," EastWest Center, Energy Advisory No. 192 (15 January 1997) Honolulu, HI.

29 Edward W. Merrow: “An Analysis of Cost Improvement in Chemical Process Technologies,” DOE paper R3357-DOE (May 1989).

30 F.J. Stermole and J.M. Stermole, Economic Evaluation and Investment Decision Methods, eighth edition, Golden, Colorado: Investment Evaluations Corporation (1993) 215-216.

31 U.S. Department of Energy, Alaska Oil and Gas - Energy Wealth or Vanishing Opportunity?, DOE/ID/01570H1 (January 1991) 